\title{
Intuitionistic Fuzzy Decision Support Based on EDAS and Grey Relational Degree for Historic Bridges Reconstruction Priority
}

\section{Katarina Rogulj ( $\sim$ katarina.rogulj@gradst.hr)}

University of Split Faculty of Civil Engineering and Architecture: Sveleuciliste u Splitu Fakultet gradevinarstva arhitekture i geodezije https://orcid.org/0000-0002-3717-8000

Jelena Kilić Pamuković

University of Split Faculty of Civil Engineering and Architecture: Sveleuciliste u Splitu Fakultet gradevinarstva arhitekture i geodezije

Jurgita Antucheviciene

Vilnius Gediminas Technical University: Vilniaus Gedimino Technikos Universitetas

Edmundas Kazimieras Zavadskas

Vilnius Gediminas Technical University: Vilniaus Gedimino Technikos Universitetas

\section{Research Article}

Keywords: decision support model, intuitionistic fuzzy theory, EDAS, grey relational degree, historic pedestrian bridges, reconstruction priority

Posted Date: January 31st, 2022

DOI: https://doi.org/10.21203/rs.3.rs-1164217/v1

License: (9) This work is licensed under a Creative Commons Attribution 4.0 International License. Read Full License 


\title{
Intuitionistic Fuzzy Decision Support Based on EDAS and Grey Relational Degree for Historic Bridges Reconstruction Priority
}

\author{
Katarina Rogulja, , Jelena Kilić Pamukovića , Jurgita Antucheviciene ${ }^{\text {b }}$, Edmundas Kazimieras Zavadskas ${ }^{\text {c }}$ \\ ${ }^{a}$ Faculty of Civil Engineering, Architecture and Geodesy, \\ University of Split, Matice hrvatske 15, 21000 Split, Croatia \\ ${ }^{\mathrm{b}}$ Department of Construction Management and Real Estate, \\ Vilnius Gediminas Technical University, Sauletekio al. 11, LT-10223 Vilnius, Lithuania \\ ${ }^{\mathrm{c}}$ Institute of Sustainable Construction, \\ Vilnius Gediminas Technical University, Sauletekio al. 11, LT-10223 Vilnius, Lithuania
}

\begin{abstract}
Bridge management includes all actions in the life cycle of bridge, in order to insure its safety, stability and functionality. Numerous problems have been identified that are primarily related to the organization of planning and the role of decision-making in reconstruction planning of the historic pedestrian bridges. The planning process of reconstruction of these bridges is crucial due to increased traffic load, poor condition or damage of bridges. Some of these bridges are part of the cultural heritage, while some are unfairly neglected. The motivation for this research arose from the need to establish the priority for the reconstruction of historic pedestrian bridges to achieve their safety, stability, functionality, and cultural preservation. A new decision support model based on intuitionistic fuzzy group decision-making to the multicriteria analysis of the historic pedestrian bridges reconstruction planning is created. The model combines multicriteria method Evaluation Based on Distance from Average Solution and grey relational degree (GRD) with intuitionistic fuzzy theory. Three relevant decision groups of experts are formed, with the knowledge and expertise in the area of research problematic, establishing criteria for the evaluation. A new approach of consistency of criteria weights is proposed. The intuitionistic fuzzy likelihood function is developed for the aggregation of evaluations of bridges. Furthermore, GRD values are calculated to determine the reconstruction priority ranking of bridges for each decision group. The final ranking is defined by integrating Integer Linear Programming (ILP) and Ant Colony Optimization (ACO), determining spatial-functional, time, and financial constraints.
\end{abstract}

Keywords: decision support model, intuitionistic fuzzy theory, EDAS, grey relational degree, historic pedestrian bridges, reconstruction priority

\section{Introduction}

The challenging task for engineers and conservatives is the protection of the buildings under the cultural heritage. Usually, these buildings are neglected and no proper managerial activities are provided for them. Among these buildings are historic bridges that require major or extensive remediation activities to ensure their safety, stability and functionality. Considering that most of them are exposed to a long period of negligence and to environmental and anthropological impacts, their elements need to be preserve from degradation, and for this reason adequate conservation and precedence to their values must be specified. Most of these bridges are derelict and no proper maintenance is conducted. As modern civilization requires more intensive traffic flow, it is important to make this bridges more functional and adaptable to new requirements, to extend their life cycle, and to preserve their historical importance. Due to all mentioned, adequate materials and technologies are needed during reconstruction or maintenance to keep their authenticity. Planning their recovery demands qualitative and thorough decisions among engineers, conservatives, and project managers, which is not an easy mission. Before the implementation of any reconstruction activity on these bridges, all regulations of conservation and local spatial development plans need to be taken into account. Attention should also be given to the fact, that historic bridges are assets that need not only conservative protection but also their socio-economic features. Which one of the bridges has priority in reconstruction is a decision that demands objective and thoughtful judgements of various aspects of an interdisciplinary nature. Using decision support model is effective tool which can systematic and synthetically describe fundamental issues when it comes to resolving complex types of problems of decision-making process. Objective and impartial decision-making is often compound and challenging in most of the construction projects, and it requires support by various experts from different engineering fields. Additional difficulties arise during the establishment of a corresponding set of criteria as one of the parts of decision support model (RadziszewskaZielina and Sladowski, 2017).

\footnotetext{
${ }^{1}$ Corresponding author: Faculty of Civil Engineering, Architecture and Geodesy, University of Split, Matice hrvatske 15, 21000 Split, Croatia, e-mail: katarina.rogulj@gradst.hr
} 
In spite of restrictions such are technical, environmental, financial or socio-economical, with the decision support principles, it can be easy for managers to define the most appropriate activity of reconstruction for each bridge. Since planning and decision-making are the main components of construction management, the planning of recovery of historic pedestrian bridges is important due to the management quality. Assessment of bridge safety and functionally is a multicriteria decision-making (MCDM) task, that deals with the assessment of criteria such as safety, functionality, cultural preservation, environmental impact, stability etc. Therefore, MCDM approach can be used for bridge safety assessment.

The demanding nature of the observed problem motivated authors to examine the possibility of forming a unique decision support (DS) model that would upgrade group decision-making to the reconstruction planning of historic pedestrian bridges. Group decision-making is used in tasks of selection of the best alternative from the observed set of alternatives or the priority ranking of feasible alternatives. In both tasks, group decision-making is implemented via attitudes and opinions of various decision makers (Wang et al, 2020). To enable such a group decision making, a new DS model is created that integrates an intuitionistic fuzzy theory with multicriteria method Evaluation of the Distance from the Average Solution (EDAS) and grey relational degree (GRD). The EDAS method (Keshavarz Ghorabaee et al., 2015) uses the average solution for evaluating the alternatives. It is based on measuring a positive distance from average (PDA) and a negative distance from average (NDA) when evaluating alternatives. The alternative with a higher value of PDA and smaller of NDA is selected as the best one. It is useful for problems with multiple conflicting criteria whose generation and evaluation are often uncertain and vagueness. The GRD is defined from Grey Relational Analysis (GRA). It is introduced by Deng (1989) as a multicriteria procedure to evaluate the uncertain relations between the alternatives using criteria. It is a process of grey knowledge, which deals with the indistinct and vagueness information on different parameters and diverse environment. It requires simple and straightforward assessment with reasonable amount of interpretative data. Theory of GRA has been widely applied in some uncertain problems as decision making, pattern recognition and alike, particularly under the discrete data and fuzzy information (Stanjukić et al, 2017). It is used to determine the vicinity to the ideal solution and the remoteness to the anti-ideal solution, respectively.

The process of the proposed DS model is illustrated through decision-making to the historic pedestrian bridges remediation as socially sensitive and very ill structure problem. Transparent decisions with the lowest predicted losses are crucial for managers (Rashidi, Lemass and Gibson, 2010). The objective and impartial decision-making is a difficult task, as in each industry so it is in construction engineering and cultural heritage management. It is complex and time-consuming process due to the comprehensive construction projects character, and it must be supported by experts from different areas of the construction industry. Most of the difficulties occur in the definition of a suitable set of criteria needed in the group decision-making process (Li et al, 2009). The major contributions and novelties of the research are as follows:

(i) A new decision support model under intuitionistic fuzzy theory is proposed to achieve qualitative group decision-making to solve the outranking problem of reconstruction planning of historic pedestrian bridges. Therefore, membership, non-membership, and hesitation degrees are included.

(ii) The proposed algorithm contains an extended EDAS method based on GRD, integrated into the intuitionistic fuzzy numbers.

(iii) A set of criteria is established for the alternatives assessment according to safety, stability, functionality etc. Thereby, fractional programming and intuitionistic fuzzy weighted averaging operator are used to calculate criteria weights, and thus, a consistency determination is proposed.

(iv) Final common ranking of the bridges is obtained combining Integer Linear Programming and Ant Colony Optimization, using financial, time, and spatial-functional constraints.

The research has five sections. In section two the preliminaries of intuitionistic sets and the proposed methodology are presented. In section three, numerical example of the decision support model to the historic pedestrian bridges built till the end of the Austro-Hungarian Monarchy in the Split-Dalmatian County, Croatia, is explained. In section four, the discussion is provided with sensitivity analysis and comparison with other methodologies, and the last section gives concluding remarks.

\subsection{Literature review}

Problems of multicriteria decision-making are crucial matter in comprehensive engineering, management and economics due to the complex and uncertain decision-making and disparate human thinking ability and knowledge capacity [8]. Fuzzy set theory was developed by Zadeh (1965) to cope with uncertain information. It has been applied in various areas, such as multicriteria decision making (Liu, Zhang and Jin, 2015), uncertainty definition of linguistic variables (Liu and Yu, 2014), SIS epidemic model analysis and treatment control function (Adak and Jana, 2021), bridge condition assessment (Dabous, 2008), managing disaster relief under earthquake concerns (Mohammadi et al, 2020), optimization of electrical discharge machine (Fazlollahtabar and Gholizadeh, 2019), solving multi-objective problem of manufacturing system scheduling (Huang and Süer, 2015), parametrization in the problems with vague data (Nawaz and Akram, 2021), network systems connectivity (Poulik, Das and Ghorai, 
2021), optimization of robotic flexible assembly cells scheduling using Taguchi method combined with fuzzy logic and multi-objective analysis (Abd, Abhary and Marian, 2016), definition of phytoplankton-zooplankton model using triangular fuzzy number (Meng and $\mathrm{Wu}, 2021$ ). The fuzziness arrives form vagueness, uncertainty, and incomplete information which is often present within project managers' problems (Yang and Lin, 2013). Fuzzy set concept is generalized by Atanassov (1986), and Atanassov and Gargov (1989) who provided the intuitionistic fuzzy sets (IFSs) concept. It is a quite effective way to deal with uncertainty and obscurity. Lately, more and more attention was given to IFS in different research fields. Atanassov (2017) gave a comparison of IFSs with Type-1 fuzzy sets and the possibility for the transformation of some concepts from IFSs theory to T1-FSs theory. Chen, Cheng, and Chio (2016) proposed a new fuzzy multicriteria group decision-making method using intuitionistic fuzzy sets and methodology of the evidential reasoning. Atanassov, Mavrov, and Atanassova (2014) developed a new model of intuitionistic fuzzy multicriteria decision-making called intercriteria decision making. Wei et al (2011), Wei (2010) and Hou (2010) investigated the intuitionistic fuzzy multiattribute decision-making problems with the unknown information about attribute weights. Xu (2008) focused on the dynamic intuitionistic fuzzy multiattribute decision-making problems, proposing new intuitionistic fuzzy aggregation operators. Xia and Xu (2012) developed two methods, based on entropy and cross-entropy to determine criteria weights, and proposed intuitionistic fuzzy entropy and cross-entropy measures. Lin, Yuan, and Xia (2007) proposed an approach for fuzzy multicriteria decision-making under intuitionistic fuzzy environment, with satisfiability and non-satisfiability degree of each alternative regarding a set of criteria represented by intuitionistic fuzzy sets.

Furthermore, the intuitionistic fuzzy theory was also used in sustainable energy decision-making problems (Gumus, Kucukvar and Tatari, 2016), pattern recognition (Cheng and Chang, 2015; Vlachos and Sergiagis, 2007), biparametric similarity measure (Boran and Akay, 2014), image fusion (Balasubramaniam and Ananthi, 2014) personal and supplier selection (Zhang and Liu, 2011; Boran et al. 2009), application of similarity in group decision-making (Szmidt and Kacprzyk, 2004), measuring the amount of knowledge (Szmidt and Kacprzyk, 2014), partner selection and evaluation systems of product development (Büyüközkan and Güleryüz, 2016), etc. All of the abovementioned research proposed models and methods for the specific case study and problematic using IFS theory to gain certainty and accuracy in various multicriteria and demanding tasks.

In multicriteria decision-making process combined under intuitionistic fuzzy theory, the criteria weights and alternative evaluations are formed into the intuitionistic fuzzy information, and sometimes their determination can be difficult due to the lack of time, experience, knowledge or data in the problem domain (Kahraman et al. 2017) . The traditional multicirteria methods such as EDAS might fail in dealing with the intuitionistic fuzzy multicriteria decision-making problems. For this reason, fuzzy set theory and intuitionistic fuzzy set theory is integrated into the EDAS method. Kahraman et al. (2017) applied intuitionistic fuzzy EDAS to solid waste disposal, Keshavarz Ghorabaee (2016) used extended EDAS for fuzzy MCDM to supplier selection, Li, Wang and Wang (2018) incorporated power aggregation operators with the EDAS method combined with linguistic neutrosophic theory to solve fuzzy multicriteria group decision-making problems, Ilieva, Yankova and Klisareva-Belcheva (2018) presented a new model of fuzzy EDAS modifications of distance measure to improve decision analysis. Ye, Zhan and $\mathrm{Xu}$ (2021) used tight fuzzy rough sets to obtain intuitionistic fuzzy data from uncertain data and developed a new multiatribute decision-making methodology using PROMETHEE II and EDAS method under intuitionistic fuzzy environment. Mi and Liao (2019) developed hesitant fuzzy best-worst method to define criteria weights and integrated them in the normalized form into the EDAS method. Keshavaraz Ghorabaee et al. (2017) proposed a model for evaluation of supplier and order assignment considering environmental criteria using interval type- 2 fuzzy sets and EDAS method. Ju et al. (2020) developed a new approach based on EDAS method for the selection of the optimal health-care alternatives of waste disposal. Thereat, alternatives assessments and criteria weights are determined by experts using multi-granular linguistic distribution assessments. Karatop et al. (2021) used Fuzzy Analytical Hierarchy Process, Fuzzy Failure Mode and Effect Analysis and EDAS method to defined optimal decision for the renewable energy sector in Turkey, also applying risk analysis. Peng, Dai, and Yuan (2017) proposed three approaches for the interval-valued fuzzy soft decision-making problems by Multiattributive Border Approximation Area Comparison and EDAS to solve some unreasonable conditions and promote the development of decision-making methods. On the other hand, the grey relational analysis (GRA) method (Deng, 1982) is based on analysis of different relationships between the discrete data sets and decision-making in multicriteria situations (Xu, 2008). Zhang, Jin, and Lin (2013) used intuitionistic fuzzy GRA for the multicriteria decision-making problems in which the criteria value took the form of an intuitionistic trapezoidal fuzzy number, where the criteria weight was unknown. Zhang et al. (2014) presented multiattribute decision-making approach with interval-valued intuitionistic fuzzy evaluation measures for each alternative using GRA. Dey, Pramanik, and Giri (2010) developed multicriteria group decision-making for weaver selection in Khadi institutions in an intuitionistic fuzzy environment based on GRA. Wei et al. (2011) created a model of intuitionistic fuzzy GRA for problem research on the multiattribute decision-making with intuitionistic fuzzy information in which the average weighted information is completely unknown. The above-given literature used EDAS or GRA method in a simple fuzzy or intuitionistic fuzzy form, but none of them combined these two methods and used them in intuitionistic fuzzy group decision-making. Unlike some of the presented studies with unknown criteria or attribute weights, in this 
research weights are given by each decision-maker, and aggregated group weights are calculated at the beginning of the proposed model, and then further used to gain GRD for each alternative.

The advantage of the new developed model regarding presented studies in the literature is that it is applied on the more complex and ill-structure problem, with multiple criteria and alternatives which proves that the research is more adaptive to higher demand problems. It is evident from the research in the literature review that EDAS based on GRD has not been used to solve the multicriteria problem in integration with the intuitionistic fuzzy theory, especially in the field of construction engineering and management. Therefore, it is a significant research contribution and important topic to create a new decision-making approach applying EDAS and GRD under intuitionistic fuzzy environment in decision-making to rank and obtain the most indispensable historic bridge for the remediation. Such decision-making approach will avoid the deficiency of the traditional multicriteria decisionmaking procedure and form a new concept of intuitionistic fuzzy decision information. Fusing EDAS with GRD authors found very useful for this and similar problems because both methods can deal with complex multicriteria issues. On the one hand, the EDAS method calculates the distance of each alternative from the average solution, it is more efficient and accessible. The problems of construction engineering and management, with various conflicting criteria, multiple alternatives, multiple decision groups with different professions, and within each group there are multiple stakeholders with different styles, opinions and, experiences, tend to effective and practical solutions that are less time consuming. On the other hand, GRD belongs to grey system theory, and is suitable when it comes to problems with compound interrelationships among multiple factors and variables, and it solves MCDM problems by combining introduced criteria values considered for every alternative into the single value. This way, alternatives with multiple conflicting criteria can be easily compared using GRD. Besides, for the proposed group decision-making problem, the authors decided to apply an intuitionistic fuzzy theory because complex construction management problems, are often based on imprecise and uncertain or incomplete information. For this reason, to achieve a tractable and robust solution, it is inevitable to reach for the methodology that will utilize the minimum tolerance for imprecision and uncertainty in achieving solutions to ill-structured decision-making problems. Intuitionistic fuzzy theory, judging by its nature, has shown to be the most appropriate for this type of challenge. First, unlike classic fuzzy theory, it is suitable for the large size of decision-making problems, and secondly, it clearly emphasizes the uncertainty, and what is most important hesitation, of decision maker's assessment. Any large size problem is difficult to evaluate by standard scales, there is always a level of reluctance in an assessment and final decision. Because of this, intuitionistic fuzzy theory indicates this uncertainty by defining the membership, non-membership, and hesitation degree of a given decision. This way, addressing the benefits of intuitionistic fuzzy theory, it is clear why is it important to use for solving the high-level complexity problem of the historic pedestrian bridges remediation group decision-making.

\section{Materials and methods}

In the following section, some basic facts and procedures related to intuitionistic fuzzy sets (IFSs) are given. Firstly, the IFSs, and intuitionistic fuzzy weighted averaging operators are defined.

\subsection{Preliminaries of intuitionistic fuzzy sets}

IFS theory is introduced by Atanassov (1986) and is an extension of the classical Fuzzy Set Theory which deals with uncertainty and duality. Intuitionistic fuzzy set $\alpha$ in a finite set $X$ can be written as:

$$
\alpha=\left\{<x, \mu_{\alpha}(x), \gamma_{\alpha}(x)>\mid x \in X\right\}
$$

where $\mu_{\alpha}(x): \mathrm{X} \rightarrow[0,1], \gamma_{\alpha}(x): \mathrm{X} \rightarrow[0,1]$ are membership function and non-membership function, respectively, of element $x \in X$ of set $\alpha$, such that:

$$
0 \leq \mu_{\alpha}(x)+\gamma_{\alpha}(x) \leq 1
$$

The third parameter of IFS is $\pi_{\alpha}(x)$, known as the intuitionistic fuzzy index or hesitation degree that denotes belonging of $x$ to $\alpha$ :

$$
\pi_{\alpha}(x)=1-\mu_{\alpha}(x)-\gamma_{\alpha}(x)
$$

And it is obvious that for every $x \in X$ :

$$
0 \leq \pi_{\alpha}(x) \leq 1
$$

If the $\pi_{\alpha}(x)$ is small, then $x$ is more certain. But if $\pi_{\alpha}(x)$ is great, then $x$ is more uncertain. 
When $\mu_{\alpha}(x)=1-\gamma_{\alpha}(x)$ for all elements of the universe, the ordinary fuzzy set concept is regain [64].

Definition 1. (Liao and $\mathrm{Xu}, 2014)$ Let $\alpha=\left(\mu_{\alpha}(x), \gamma_{\alpha}(x), \pi_{\alpha}(x)\right)$ be an intuitionistic fuzzy set (IFS), where $\mu_{\alpha}(x) \in[0,1], \gamma_{\alpha}(x) \in[0,1]$, and $\pi_{\alpha}(x)=1-\mu_{\alpha}(x)-\gamma_{\alpha}(x)$.

Definition 2. (Gumus, Kucukvar and Tatari, 2016) Let $\alpha=\left(\mu_{\alpha}, \gamma_{\alpha}, \pi_{\alpha}\right)$ and $\beta=\left(\mu_{\beta}, \gamma_{\beta}, \pi_{\beta}\right)$ be two IFSs of the set $X$, then the following statement are defined as follows:

$$
\begin{gathered}
\alpha \cdot \beta=\left(\mu_{\alpha} \cdot \mu_{\beta}, \gamma_{\alpha}+\gamma_{\beta}-\gamma_{\alpha} \cdot \gamma_{\beta}, 1-\mu_{\alpha} \cdot \mu_{\beta}-\gamma_{\alpha}-\gamma_{\beta}+\gamma_{\alpha} \cdot \gamma_{\beta}\right) \\
\alpha^{\lambda}=\left(\mu_{\alpha}\right)^{\lambda}, 1-\left(1-\gamma_{\alpha}\right)^{\lambda},\left(1-\gamma_{\alpha}\right)^{\lambda}-\left(\mu_{\alpha}\right)^{\lambda}, \lambda>0 \\
\lambda \alpha=1-\left(1-\mu_{\alpha}\right)^{\lambda},\left(\gamma_{\alpha}\right)^{\lambda},\left(1-\mu_{\alpha}\right)^{\lambda}-\left(\gamma_{\alpha}\right)^{\lambda}, \lambda>0
\end{gathered}
$$

\subsection{Proposed DS model}

In this study, an integrated DS model for group multicriteria decision-making problem of historic bridges remediation planning is proposed. It is formed using intuitionistic fuzzy theory fused with EDAS method and GRD to obtain bridge ranking by each decision group (DG) and common ranking of bridges obtained by ILP-ACO simulation. The proposed model consists of 17 steps. The steps are given below and presented in details in Figures 1 and 2, where Figure 1 shows steps from 1 to 14, and Figure 2, from 15 to 17.

Step 1. Definition of alternatives and criteria.

To start any MCDM procedure, it is necessary to determine the optimal alternative within the analysed set of alternatives $A=\left\{A_{1}, A_{2}, \ldots, A_{m}\right\}$ evaluated by set of criteria $C=\left\{C_{1}, C_{2}, \ldots, C_{n}\right\}$. Groups of experts $G=$ $\left\{G_{1}, G_{2}, \ldots, G_{g}\right\}$ consisting of experts/decision makers $E=\left\{E_{1}, E_{2}, \ldots, E_{p}\right\}$ have been formed to obtain the optimal alternative(s).

Step 2. Calculate DMs' weights.

Definition 3. (Boran et al, 2009) There are $p$ decision makers (DM) in decision group (DG). The weights of DMs are given as linguistic values expressed by IFNs. If $A_{t}=\left(\mu_{t}, \gamma_{t}, \pi_{t}\right)$ is an IFN of the $t$ th DM's rating, then the weight of the $t$ th DM can be obtained as:

$$
\lambda_{t}=\frac{\left(\mu_{t}+\pi_{t}\left(\frac{\mu_{t}}{\mu_{t}+\gamma_{t}}\right)\right)}{\sum_{t=1}^{p}\left(\mu_{t}+\pi_{t}\left(\frac{\mu_{t}}{\mu_{t}+\gamma_{t}}\right)\right)}
$$

where $\sum_{t=1}^{p} \lambda_{t}=1$.

Step 3. Determine criteria weights using intuitionistic fuzzy judgement matrix.

All criteria may not necessary be of the equal importance, and for this reason a set of ratings needs to be determine that will be used for criteria weights. Suppose the DM provides intuitionistic fuzzy judgements for a pairwise comparison matrix.

Definition 4. Let $A=\left(a_{i j}\right)_{n \times n}$ be a judgement matrix where $a_{i j}=\left(\mu_{i j}, \gamma_{i j}, \pi_{i j}\right), \mathrm{i}, \mathrm{j}=1,2, \ldots, \mathrm{n}$, and $\mu_{i j}$ denotes the preference degree of the criterion $x_{i}$ over the criterion $x_{j}$ given by DM, $\gamma_{i j}$ denotes the preference degree of the criterion $x_{j}$ over the criterion $x_{i}$ by DM, $\pi_{i j}$ denotes uncertainty degree.

Step 4. Create an intuitionistic fuzzy preference relation based on multiplicative consistency.

Definition 5. Let $\widetilde{\omega}=\left(\widetilde{\omega_{1}}, \widetilde{\omega_{2}}, \ldots, \widetilde{\omega_{n}}\right)^{T}=\left(\left(\widetilde{\omega}_{1}^{(\mu)}, \widetilde{\omega}_{1}^{(\gamma)}\right),\left(\widetilde{\omega}_{2}^{(\mu)}, \widetilde{\omega}_{2}^{(\gamma)}\right), \ldots .,\left(\widetilde{\omega}_{n}^{(\mu)}, \widetilde{\omega}_{n}^{(\gamma)}\right)\right)^{T}$ be an intuitionistic fuzzy priority weight vector of the IFPR $\widetilde{R}=\left(\widetilde{r_{l \jmath}}\right)_{n \times n}$, where $\widetilde{\omega}_{i}=\left(\widetilde{\omega}_{i}^{(\mu)}, \widetilde{\omega}_{i}^{(\gamma)}\right)(i=1,2, \ldots, n)$ is an intuitionistic fuzzy value (IFV), and it satisfies $\widetilde{\omega}_{i}^{(\mu)}, \widetilde{\omega}_{i}^{(\gamma)} \in[0,1]$ and $\widetilde{\omega}_{i}^{(\mu)}+\widetilde{\omega}_{i}^{(\gamma)} \leq 1$. The membership and non-membership degree of the criteria $x_{i}$ as an intuitionistic fuzzy importance are $\widetilde{\omega}_{i}^{(\mu)}$ and $\widetilde{\omega}_{i}^{(\gamma)}$, respectively. An intuitionistic 
fuzzy weight vector $\widetilde{\omega}=\left(\widetilde{\omega_{1}}, \widetilde{\omega_{2}}, \ldots, \widetilde{\omega_{n}}\right)^{T}$ with $\widetilde{\omega}_{i}=\left(\widetilde{\omega}_{i}^{(\mu)}, \widetilde{\omega}_{i}^{(\gamma)}\right), \widetilde{\omega}_{i}^{(\mu)}, \widetilde{\omega}_{i}^{(\gamma)} \in[0,1]$ and $\widetilde{\omega}_{i}^{(\mu)}+\widetilde{\omega}_{i}^{(\gamma)} \leq 1$ for $(i=1,2, \ldots, n)$ is normalized if it satisfies given condition (Wang, 2013; Liao and Xu, 2014):

$$
\sum_{j=1, j \neq i}^{n} \omega_{j}^{(\mu)} \leq \omega_{i}^{(\gamma)}, \omega_{i}^{(\mu)}+n-2 \geq \sum_{j=1, j \neq i}^{n} \omega_{j}^{(\gamma)} \text { for all } i=1,2, \ldots, n .
$$

An intuitionistic fuzzy preference relation $\widetilde{R}=\left(r_{i j}\right)_{n \times n}$ is called multiplicative consistent if the following multiplicative transitivity is satisfied:

$$
r_{i j} \cdot r_{j k} \cdot r_{k i}=r_{i k} \cdot r_{k j} \cdot r_{j i}, \quad i, j, k=1,2, \ldots, n .
$$

Multiplicative consistent IFPR is established as follows:

$$
\widetilde{p_{\imath \jmath}}=\left(\tilde{p}_{i j}^{(\mu)}, \tilde{p}_{i j}^{(\gamma)}\right)= \begin{cases}(0.5,0.5), & \text { if } i=j \\ \left(\frac{2 \omega_{i}^{(\mu)}}{\omega_{i}^{(\mu)}-\omega_{i}^{(\gamma)}+\omega_{j}^{(\mu)}-\omega_{j}^{(\gamma)}+2}, \frac{2 \omega_{j}^{(\mu)}}{\omega_{i}^{(\mu)}-\omega_{i}^{(\gamma)}+\omega_{j}^{(\mu)}-\omega_{j}^{(\gamma)}+2}\right), & \text { if } i \neq j\end{cases}
$$

Where $\omega_{i}^{(\mu)}, \omega_{i}^{(\gamma)} \in[0,1], \omega_{i}^{(\mu)}+\omega_{i}^{(\gamma)} \leq 1, \sum_{j=1, j \neq i}^{n} \omega_{j}^{(\mu)} \leq \omega_{i}^{(\gamma)}$, and $\omega_{i}^{(\mu)}+n-2 \geq \sum_{j=1, j \neq i}^{n} \omega_{j}^{(\gamma)}$, for all $i=$ $1,2, \ldots, n$.

If there is a normalized intuitionistic fuzzy weight vector $\widetilde{\omega}=\left(\widetilde{\omega_{1}}, \widetilde{\omega_{2}}, \ldots, \widetilde{\omega_{n}}\right)^{T}$, for IFPR $\widetilde{R}=\left(\widetilde{r_{l j}}\right)_{n \times n}$ and $\widetilde{r_{l j}}=$ $\left(\mu_{i j}, \gamma_{i j}\right)$, defined as:

$$
\widetilde{r_{l \jmath}}=\left(\mu_{i j}, \gamma_{i j}\right)= \begin{cases}(0.5,0.5), & \text { if } i=j \\ \left(\frac{2 \omega_{i}^{(\mu)}}{\omega_{i}^{(\mu)}-\omega_{i}^{(\gamma)}+\omega_{j}^{(\mu)}-\omega_{j}^{(\gamma)}+2}, \frac{2 \omega_{j}^{(\mu)}}{\omega_{i}^{(\mu)}-\omega_{i}^{(\gamma)}+\omega_{j}^{(\mu)}-\omega_{j}^{(\gamma)}+2}\right), & \text { if } i \neq j\end{cases}
$$

Where $\omega_{i}^{(\mu)}, \omega_{i}^{(\gamma)} \in[0,1], \omega_{i}^{(\mu)}+\omega_{i}^{(\gamma)} \leq 1, \sum_{j=1, j \neq i}^{n} \omega_{j}^{(\mu)} \leq \omega_{i}^{(\gamma)}$, and $\omega_{i}^{(\mu)}+n-2 \geq \sum_{j=1, j \neq i}^{n} \omega_{j}^{(\gamma)}$, for all $i=$ $1,2, \ldots, n$, then $\widetilde{R}=\left(\widetilde{r}_{l J}\right)_{n \times n}$ is multiplicative consistent IFPR.

In decision making is often difficult to obtain multiplicative consistency, and for that reason it is expected that the deviation between given IFPR and its associated multiplicative consistent IFPR be as small as possible. Introducing the deviation variables $\varepsilon_{i j}$ and $\xi_{i j}$, and smaller the absolute deviations are $\left|\varepsilon_{i j}\right|$ and $\left|\xi_{i j}\right|$, respectively, the more exact is result. Using fractional programming, the intuitionistic fuzzy weights can be obtained as:

$$
\begin{gathered}
\operatorname{Min} Z=\sum_{i=1}^{n-1} \sum_{j=i+1}^{n}\left(\varepsilon_{i j}^{+}+\varepsilon_{i j}^{-}+\xi_{i j}^{+}+\xi_{i j}^{-}\right) \\
\text {s.t. }\left\{\begin{array}{c}
\frac{2 \omega_{i}^{(\mu)}}{\omega_{i}^{(\mu)}-\omega_{i}^{(\gamma)}+\omega_{j}^{(\mu)}-\omega_{j}^{(\gamma)}+2}-\mu_{i j}-\varepsilon_{i j}^{+}+\varepsilon_{i j}^{-}=0, \quad i=1,2, \ldots, n-1 ; j=i+1, \ldots, n \\
\frac{2 \omega_{j}^{(\mu)}}{\omega_{i}^{(\mu)}-\omega_{i}^{(\gamma)}+\omega_{j}^{(\mu)}-\omega_{j}^{(\gamma)}+2}-\gamma_{i j}-\xi_{i j}^{+}+\xi_{i j}^{-}=0, \quad i=1,2, \ldots, n-1 ; j=i+1, \ldots, n \\
\omega_{i}^{(\mu)}, \omega_{i}^{(\gamma)} \in[0,1], \omega_{i}^{(\mu)}+\omega_{i}^{(\gamma)} \leq 1, \quad i=1,2, \ldots, n-1 \\
\sum_{j=1, j \neq i}^{n} \omega_{j}^{(\mu)} \leq \omega_{i}^{(\gamma)}, \\
\omega_{i}^{(\mu)}+n-1 \geq \sum_{j=1, j \neq i}^{n} \omega_{j}^{(\gamma)}, \quad i=1,2, \ldots, n-1 \\
\varepsilon_{i j}^{+} \geq 0, \varepsilon_{i j}^{-} \geq 0, \xi_{i j}^{+} \geq 0, \xi_{i j}^{-} \geq 0, \varepsilon_{i j}^{+} \cdot \varepsilon_{i j}^{-}=0, \xi_{i j}^{+} \cdot \xi_{i j}^{-}=0, \quad i=1,2, \ldots, n-1 ; j=i+1, \ldots
\end{array}\right.
\end{gathered}
$$


The IFPR $\tilde{R}=\widetilde{\left(r_{l j}\right)_{n \times n}}$ is multiplicative consistent if and only if $\mathrm{Z}=0$, and $\mathrm{Z}$ is the optimal value of the objective function. Since such excellent multiplicative consistent IFPR is hard for the experts to establish, a consistency measure $C_{\tilde{R}}$ is obtained (with definition of consistency threshold $\delta$ ) to measure the degree of consistency for the IFPR $\tilde{R}$. It is very important to include uncertainty degree when calculating distance between two IFSs.

Step 5. Determination of consistency.

Definition 6. Let $A$ and $B$ be two IFSs, then the distance measure between A and B is defined as $d(A, B)$, which satisfies the following properties:

(i) $0 \leq d(A, B) \leq 1$;

(ii) $d(A, B)=0$ iff $\mathrm{A}=\mathrm{B}$;

(iii) $d(A, B)=d(B, A)$.

Szmidt and Kacprzyk (2000) proposed the following normalized distance measures between A and B: The normalized Hamming distance is given as follows:

$$
d(A, B)=\frac{1}{2 n} \sum_{i=1}^{n}\left(\left|\mu_{A}-\mu_{B}\right|+\left|\gamma_{A}-\gamma_{B}\right|+\left|\pi_{A}-\pi_{B}\right|\right)
$$

The normalized Euclidean distance:

$$
d(A, B)=\sqrt{\frac{1}{2 n} \sum_{i=1}^{n}\left(\left|\mu_{A}-\mu_{B}\right|^{2}+\left|\gamma_{A}-\gamma_{B}\right|^{2}+\left|\pi_{A}-\pi_{B}\right|^{2}\right)}
$$

Extending (14) and (15) into generalized IF normalized distance and using generalized mean operator by Dyckhoff and Pedrycz (1984) as follows:

(14) and (15) can be written as:

$$
M\left(A_{1}, \ldots A_{n}\right)=\left(\frac{1}{n} \sum_{i=1}^{n} a_{i}^{\lambda}\right)^{1 / \lambda}
$$

$$
d(A, B)=\sqrt[\lambda]{\frac{1}{n} \sum_{i=1}^{n}\left(\left|\mu_{A}-\mu_{B}\right|^{\lambda}+\left|\gamma_{A}-\gamma_{B}\right|^{\lambda}+\left|\pi_{A}-\pi_{B}\right|^{\lambda}\right)}
$$

Using Hausdorff distance in generalized IF normalized form as:

$$
d(A, B)=\sqrt[\lambda]{\frac{1}{n} \sum_{i=1}^{n}\left(\max _{j}\left(\left|\mu_{A}-\mu_{B}\right|^{\lambda},\left|\gamma_{A}-\gamma_{B}\right|^{\lambda},\left|\pi_{A}-\pi_{B}\right|^{\lambda}\right)\right)}
$$

If $d(A, B)$ satisfies the following properties:

(i) $0 \leq d(A, B) \leq 1$;

(ii) $d(A, B)=0$ iff $A=B$;

(iii) $d(A, B)=d(B, A)$;

(iv) If $A \subseteq B \subseteq C \quad A, B, C \in \operatorname{IFs}(x)$ then $d(A, C) \geq d(A, B)$ and $d(A, C) \geq d(B, C)$, then $\mathrm{d}(\mathrm{A}, \mathrm{B})$ is a distance measure between IFSs $A$ and $B$.

Observing (17) and (18), a new generalized IF normalized distance between two IFSs can be proposed as follows: 
$d(A, B)=\sqrt[\lambda]{\frac{1}{n} \sum_{i=1}^{n}\left(\frac{\left|\mu_{A}-\mu_{B}\right|^{\lambda}+\left|\gamma_{A}-\gamma_{B}\right|^{\lambda}+\left|\pi_{A}-\pi_{B}\right|^{\lambda}}{6}+\frac{\max _{j}\left(\left|\mu_{A}-\mu_{B}\right|^{\lambda},\left|\gamma_{A}-\gamma_{B}\right|^{\lambda},\left|\pi_{A}-\pi_{B}\right|^{\lambda}\right)}{3}\right)}$

Where $A=\left\{\left\langle x_{i}, \mu_{A}\left(x_{i}\right), \gamma_{A}\left(x_{i}\right), \pi_{A}\left(x_{i}\right)\right\rangle \mid x_{i} \in X\right\}, B=\left\{\left\langle x_{i}, \mu_{B}\left(x_{i}\right), \gamma_{B}\left(x_{i}\right), \pi_{B}\left(x_{i}\right)\right\rangle \mid x_{i} \in X\right\}$. It is obvious that $d(A, B)$ satisfies properties $1-3$, and for property 4 there is:

(i) $\left|\mu_{A}-\mu_{C}\right| \geq\left|\mu_{A}-\mu_{B}\right|$;

(ii) $\left|\gamma_{A}-\gamma_{C}\right| \geq\left|\gamma_{A}-\gamma_{B}\right|$;

(iii) $\left|\pi_{A}-\pi_{C}\right| \geq\left|\pi_{A}-\pi_{B}\right|$.

Which follows:

$$
\begin{array}{r}
\frac{\left|\mu_{A}-\mu_{C}\right|^{\lambda}+\left|\gamma_{A}-\gamma_{C}\right|^{\lambda}+\left|\pi_{A}-\pi_{C}\right|^{\lambda}}{6}+\frac{\max _{j}\left(\left|\mu_{A}-\mu_{C}\right|^{\lambda},\left|\gamma_{A}-\gamma_{C}\right|^{\lambda},\left|\pi_{A}-\pi_{C}\right|^{\lambda}\right)}{3} \\
\quad \geq \frac{\left|\mu_{A}-\mu_{B}\right|^{\lambda}+\left|\gamma_{A}-\gamma_{B}\right|^{\lambda}+\left|\pi_{A}-\pi_{B}\right|^{\lambda}}{6}+\frac{\max _{j}\left(\left|\mu_{A}-\mu_{B}\right|^{\lambda},\left|\gamma_{A}-\gamma_{B}\right|^{\lambda},\left|\pi_{A}-\pi_{B}\right|^{\lambda}\right)}{3}
\end{array}
$$

Which proves property 4 . So it is clear that $d(A, B)$ is the distance measure between IFSs A and B.

Assume that $R=\left(r_{i j}\right)_{n \times n}$ is an IFPR with $r_{i j}=\left(\mu_{i j}, \gamma_{i j}, \pi_{i j}\right), \mathrm{i}, \mathrm{j}=1,2, \ldots, \mathrm{n}$, then $R$ is an acceptable multiplicative consistent IFPR if:

$$
d\left(R, R^{*}\right) \leq \delta
$$

Where $d\left(R, R^{*}\right)$ is distance measure between given $R$ and its corresponding multiplicative consistent IFPR $R^{*}$, and $\delta$ is consistency threshold. As there is a need to calculate the differences only over the upper triangular elements, the denominator is used as $(n-1)(n-4)$. Finally, the distance between $R$ and $R^{*}$, can be written as:

$$
d\left(R, R^{*}\right)=\sqrt[\lambda]{\frac{1}{(n-1)(n-4)} \sum_{i=1}^{n}\left(\frac{\left|\mu_{A}-\mu_{B}\right|^{\lambda}+\left|\gamma_{A}-\gamma_{B}\right|^{\lambda}+\left|\pi_{A}-\pi_{B}\right|^{\lambda}}{6}+\frac{\max _{j}\left(\left|\mu_{A}-\mu_{B}\right|^{\lambda},\left|\gamma_{A}-\gamma_{B}\right|^{\lambda},\left|\pi_{A}-\pi_{B}\right|^{\lambda}\right)}{3}\right)}
$$

Where $\lambda$ is the DM's weight given by (8). Then the consistency measure $C_{\tilde{R}}$ can be calculated as:

$$
C_{\tilde{R}}=1-d\left(R, R^{*}\right) \geq \delta
$$

If the determined consistency threshold $\delta$ is not achieved, then the IFPRs have no acceptable consistency, and DMs are asked to go back to step 3, and define new criteria weights. The consistency is taken as $\delta=0.90$.

Step 6. Determine aggregated IF criteria weights.

Criteria importance is denoted by $\omega$ and opinions of all DMs in each DG about each criterion need to be gathered together after the criteria weight consistency is established. As the IFWGA operator highlights the individual influence, and for that reason is more sensitive to $w_{j} \in \operatorname{IFS}(\mathrm{j}=1,2, \ldots, \mathrm{n})$, it is proposed for calculating the weights of criteria.

Definition 7. (Xu, 2007a) If $\omega_{j}^{(t)}=\left(\mu_{j}^{(t)}, \gamma_{j}^{(t)}, \pi_{j}^{(t)}\right)$ is an intuitionistic fuzzy number given to criterion $x_{j}$ by the $t$ th $\mathrm{DM}$, then the aggregated criteria weights, using IFWGA operator, can be defined as follows:

$$
\begin{aligned}
\omega_{j}{ }^{(g)} & =I F W G A_{\lambda}\left(\omega_{j}{ }^{(1)}, \omega_{j}{ }^{(2)}, \ldots, \omega_{j}{ }^{(p)}\right)=\left(\omega_{j}{ }^{(1)}\right)^{\lambda_{1}} \otimes\left(\omega_{j}{ }^{(2)}\right)^{\lambda_{2}} \otimes \ldots \otimes\left(\omega_{j}{ }^{(p)}\right)^{\lambda_{p}} \\
& =\left[\prod_{j=1}^{p}\left(\mu_{j}^{(t)}\right)^{\lambda_{t}}, 1-\prod_{j=1}^{p}\left(1-\gamma_{j}^{(t)}\right)^{\lambda_{t}}, \prod_{j=1}^{p}\left(1-\gamma_{j}^{(t)}\right)^{\lambda_{t}}-\prod_{j=1}^{p}\left(\mu_{j}^{(t)}\right)^{\lambda_{t}}\right]
\end{aligned}
$$


Where $\omega=\left(\omega_{1}, \omega_{2}, \ldots, \omega_{j}\right)$ and $\omega_{j}=\left(\mu_{j}, \gamma_{j}, \pi_{j}\right)(\mathrm{j}=1,2, \ldots, \mathrm{n}), \mu_{j}=\prod_{j=1}^{p}\left(\mu_{j}^{(t)}\right)^{\lambda_{t}}, \gamma_{j}=1-\prod_{j=1}^{p}\left(1-\gamma_{j}^{(t)}\right)^{\lambda_{t}}$, $\pi_{j}=\prod_{j=1}^{p}\left(1-\gamma_{j}^{(t)}\right)^{\lambda_{t}}-\prod_{j=1}^{p}\left(\mu_{j}^{(t)}\right)^{\lambda_{t}}$, and $\lambda$ is obtained by (8).

Step 7. Calculate high accuracy function.

If $\mu_{i j} \in[0,1]$ and $\gamma_{i j} \in[0,1], \mu_{j i}=\gamma_{i j}, \gamma_{j i}=\mu_{j i}, \mu_{i i}=\gamma_{i i}=0.5, \mu_{i j}+\gamma_{i j} \leq 1, \mathrm{i}, \mathrm{j}, \ldots, \mathrm{n}$, then $A$ is called intuitionistic fuzzy judgement matrix. If $\pi_{i j}=0, \mathrm{i}, \mathrm{j}, \ldots, \mathrm{n}$, then the intuitionistic fuzzy judgement matrix $A$ can be divided into following two complement judgement matrices formally $A_{1}=\left(\mu_{i j}\right)_{n \times n}$ and $A_{2}=\left(\gamma_{i j}\right)_{n \times n}$, where $\mu_{i j}, \gamma_{i j} \in[0,1], \mu_{i j}+\mu_{j i}=1, \gamma_{i j}+\gamma_{j i}=1, \mu_{i i}=\gamma_{i i}=0.5, \mathrm{i}, \mathrm{j}, \ldots, \mathrm{n}$.

Definition 8. (Ma and Hu, 1997) Let $A=\left(a_{i j}\right)_{n \times n}$ be an antisymmetric matrix, if $a_{i j}=-a_{j i}, \mathrm{i}, \mathrm{j}, \ldots, \mathrm{n}$, and $A=$ $\left(a_{i j}\right)_{n \times n}$ be a transfer matrix, if $a_{i j}=-a_{j i}, a_{i j}=a_{i k}+a_{k j}, \mathrm{i}, \mathrm{j}, \ldots, \mathrm{n}$.

Definition 9. (Cao, Wu and Liang, 2015) Let $A=\left(a_{i j}\right)_{n \times n}$ be an intuitionistic fuzzy judgement matrix, then $B=$ $\left(b_{i j}\right)_{n \times n}$ is called the score judgement matrix, where $b_{i j}=b\left(a_{i j}\right)=\mu_{i j}-\gamma_{i j}, \mathrm{i}, \mathrm{j}, \ldots, \mathrm{n}$, and $b\left(a_{i j}\right)$ is called score function of $a_{i j}$.

Definition 10. (Cao, Wu and Liang, 2015) Let $A=\left(a_{i j}\right)_{n \times n}$ be an intuitionistic fuzzy judgement matrix and $B=$ $\left(b_{i j}\right)_{n \times n}$ its score judgement matrix, then $B=\left(b_{i j}\right)_{n \times n}$ is an antisymmetric matrix, and if $b_{i j}=b\left(a_{i j}\right)=\mu_{i j}-\gamma_{i j}$, $b_{j i}=b\left(a_{j i}\right)=\mu_{j i}-\gamma_{j i}$, then $b_{i j}=\mu_{i j}-\gamma_{i j}=\gamma_{j i}-\mu_{j i}=-b_{j i}$ for all $\mathrm{i}, \mathrm{j}=1,2, \ldots, \mathrm{n}$.

Definition 11. (Zhang and $\mathrm{Xu}, 2012)$ Let $A=\left(\mu_{A}, \gamma_{A}, \pi_{A}\right)$ be an intuitionistic fuzzy number, a similarity function $S(A)$ of intuitionistic fuzzy value can be presented as follows:

And the accuracy function is:

$$
\mathrm{S}(\mathrm{A})=\frac{1-\mu_{A}}{1+\pi_{A}}
$$

$$
\mathrm{H}(\mathrm{A})=\mu_{A}+\gamma_{A}
$$

For two intuitionistic fuzzy numbers $A=\left(\mu_{A}, \gamma_{A}, \pi_{A}\right)$ and $B=\left(\mu_{B}, \gamma_{B}, \pi_{B}\right)$ there is:

(i) If $\mathrm{S}(\mathrm{A})>\mathrm{S}(\mathrm{B})$, then $\mathrm{A}>\mathrm{B}$.

(ii) If $S(A)=S(B)$, then $A=B$.

(iii) If $\mathrm{H}(\mathrm{A})>\mathrm{H}(\mathrm{B})$, then $\mathrm{A}>\mathrm{B}$.

(iv) If $\mathrm{H}(\mathrm{A})=\mathrm{H}(\mathrm{B})$, then $\mathrm{A}=\mathrm{B}$; in this case score of $\mathrm{A}$ is not better than $\mathrm{B}$. Next, the high accuracy function is defined to evaluate the degree of accuracy of IFS.

From the definition of accuracy function (25), H(A) can be also demonstrated as:

$\mathrm{H}(\mathrm{A})=\mu_{A}+\gamma_{A}=1-\pi$

The value of $\pi$ denotes a measure of hesitation. The larger $\pi$ the higher is a hesitation degree of the DM's evaluation. Consequently, the lower the value of $H(A)$, the less is degree of accuracy of the IFS of $A$. Furthermore, if accuracy function is same for two IFSs, then one set is no better than other which does not satisfy DM's requirements. For this reason, two functions, score S(A) and accuracy H(A) are added to obtain a function of high accuracy, which can give a better measure of the accuracy degree of DM's evaluation. So, using these two functions, the high accuracy to which the alternative $A_{i}$ is better than $B_{i}$ can be measured as follows (Lin, Yuan and Xia, 2006):

$$
\mathrm{F}(\mathrm{A})=\mathrm{S}(\mathrm{A})+\frac{1-\mathrm{H}(\mathrm{A})}{2}=\frac{1-\mu_{A}}{1+\pi_{A}}+\frac{\pi_{A}}{2}
$$

where $\mathrm{F}(\mathrm{A}) \in[0,1]$. The larger the value of $\mathrm{F}(\mathrm{A})$, the better is alternative $A_{i}$ over $B_{i}$.

Step 8. Evaluate the alternatives: aggregated IF decision matrix. 
Assume that $D^{(k)}=d_{i j}{ }^{(k)}{ }_{m x n}$ is an intuitionistic fuzzy decision matrix of each DM, and $\lambda=\left\{\lambda_{1}, \lambda_{2}, \ldots, \lambda_{p}\right\}$ is the each DM's importance within each group, where $\sum_{i=1}^{p} \lambda_{t}=1, \lambda_{t} \in[0,1]$. Evaluation of bridges by each DG's member must be gathered so the aggregated intuitionistic fuzzy decision matrix can be design. Let suppose that the evaluations of DMs are log-normally distributed. The aggregated evaluations of each DG are expressed as the common evaluations per logarithmic size interval with the DM's importance $\lambda_{t} \in[0,1]$, and can be formulated with the log-normal distribution as:

$$
P\left(d \mid \delta, \sigma^{2}\right)=\frac{1}{d^{\lambda} \sigma \sqrt{2 \pi}} e^{-\frac{1}{2}\left(\frac{\ln d^{\lambda}-\delta}{\sigma}\right)^{2}}
$$

Where $d_{i j}=\left(\mu_{i j}, \gamma_{i j}, \pi_{i j}\right)$ is the evaluation of each bridge by each criterion, $\mathrm{i}=1,2, \ldots, \mathrm{m}, \mathrm{j}=0,1, \ldots, \mathrm{n}$, and $\lambda_{t} \in$ $[0,1]$ is the DM's importance. To calculate likelihood of aggregated evaluations, likelihood function is used. The function of the lognormal distribution for a $d_{i j} \mathrm{~s}(\mathrm{i}=1,2, \ldots, \mathrm{m}, \mathrm{j}=1,2, \ldots, \mathrm{n})$ is derived by taking the product of the probability densities of the individual $d_{i}$ :

$$
L\left(\delta, \sigma^{2} \mid d_{1}^{\lambda_{1}}, \ldots, d_{m}^{\lambda_{t}}\right)=\prod_{i=1}^{m} \frac{1}{d_{i j}^{\lambda_{t}} \sigma \sqrt{2 \pi}} e^{-\frac{1}{2}\left(\frac{\ln d_{i j}^{\lambda_{t}}-\delta}{\sigma}\right)^{2}}, \mathrm{j}=1,2, \ldots, \mathrm{n}, \mathrm{t}=1,2, \ldots \mathrm{p}
$$

The log-likelihood function of the log-normal for the series of $d_{i j} \mathrm{~s}(\mathrm{i}=1,2, \ldots, \mathrm{m}, \mathrm{j}=1,2, \ldots, \mathrm{n})$ is then derived by taking the natural log of the likelihood function:

$$
\begin{aligned}
& \ln L\left(\delta, \sigma^{2} \mid d_{1}^{\lambda_{1}}, \ldots, d_{m}^{\lambda_{t}}\right)=\ln \left(\prod_{i=1}^{m} \frac{1}{d_{i j}^{\lambda_{t}} \sigma \sqrt{2 \pi}} e^{-\frac{1}{2}\left(\frac{\ln d_{i j}^{\lambda_{t}}-\delta}{\sigma}\right)^{2}}\right)=\ln 1-\lambda_{1} \ln d_{1}-\ln \sigma \sqrt{2 \pi}+ \\
& \left(-\frac{1}{2}\left(\frac{\lambda_{1} \ln d_{1}-\delta}{\sigma}\right)^{2}\right)+\cdots+\ln 1-\lambda_{t} \ln d_{m}-\ln \sigma \sqrt{2 \pi}+\left(-\frac{1}{2}\left(\frac{\lambda_{t} \ln d_{m}-\delta}{\sigma}\right)^{2}\right), \quad t=1,2, \ldots, p
\end{aligned}
$$

After taking derivate with respect to $\delta$, the expression is derived as:

$$
\begin{aligned}
\frac{\partial}{\partial \delta} L\left(\delta, \sigma^{2} \mid d_{1}^{\lambda_{1}}, \ldots, d_{m}^{\lambda_{t}}\right) & =\left(-\frac{1}{\sigma^{2}}\left(\lambda_{1} \ln d_{1}-\delta\right)\right)+\cdots+\left(-\frac{1}{\sigma^{2}}\left(\lambda_{t} \ln d_{m}-\delta\right)\right) \\
& =-\frac{1}{\sigma^{2}}\left(\sum_{i=1}^{m}\left(\lambda_{t} \ln d_{i j}\right)-m \delta\right), \mathrm{j}=1,2, \ldots, \mathrm{n} \quad \mathrm{t}=1,2 \ldots, \mathrm{p}
\end{aligned}
$$

Setting the derivate equal to zero, such as:

$$
\begin{aligned}
& \frac{\partial}{\partial \delta} L\left(\delta, \sigma^{2} \mid d_{1}^{\lambda_{1}}, \ldots, d_{m}^{\lambda_{t}}\right)=-\frac{1}{\sigma^{2}}\left(\sum_{i=1}^{m}\left(\lambda_{t} \ln d_{i j}\right)-m \delta\right)=0 \\
& \frac{m \delta}{\sigma^{2}}=\frac{\sum_{i=1}^{m}\left(\lambda_{t} \ln d_{i j}\right)}{\sigma^{2}} \\
& \delta=\frac{\sum_{i=1}^{m}\left(\lambda_{t} \ln d_{i j}\right)}{m}, j=1,2, \ldots, n \quad t=1,2 \ldots, p
\end{aligned}
$$

Using expression (7), $\lambda \ln d$ is defined as:

$$
\lambda \ln d=\lambda \ln (1-\mu)-\ln (1-\mu),(1-\lambda) \ln \gamma
$$

Then, IF likelihood of aggregated evaluations is defined as follows:

$$
\delta_{i j}=\frac{1}{m} \sum_{i=1}^{m}\left(1-(1-\mu)^{(1-\lambda)}\right), \frac{1}{m} \sum_{i=1}^{m}\left(1-\gamma^{(1-\lambda)}\right)
$$

Where $\mu_{i j}$ and $\gamma_{i j}$ are membership and non-membership degree, respectively and $i=1,2, \ldots, m, j=1,2, \ldots, n$ and $t=1,2, \ldots, p$.

Then, the aggregated IF decision matrix is established as: 


$$
D_{i j}{ }^{(g)}=\left[\begin{array}{cccc}
\left(\mu_{\delta_{1}}\left(d_{1}\right), \gamma_{\delta_{1}}\left(d_{1}\right), \pi_{\delta_{1}}\left(d_{1}\right)\right) & \left(\mu_{\delta_{1}}\left(d_{2}\right), \gamma_{\delta_{1}}\left(d_{2}\right), \pi_{\delta_{1}}\left(d_{2}\right)\right) & \cdots & \left(\mu_{\delta_{1}}\left(d_{n}\right), \gamma_{\delta_{1}}\left(d_{n}\right), \pi_{\delta_{1}}\left(d_{n}\right)\right) \\
\left(\mu_{\delta_{2}}\left(d_{1}\right), \gamma_{\delta_{2}}\left(d_{1}\right), \pi_{\delta_{2}}\left(d_{1}\right)\right) & \left(\mu_{\delta_{2}}\left(d_{2}\right), \gamma_{\delta_{2}}\left(d_{2}\right), \pi_{\delta_{2}}\left(d_{2}\right)\right) & \cdots & \left(\mu_{\delta_{i}}\left(d_{n}\right), \gamma_{\delta_{i}}\left(d_{n}\right), \pi_{\delta_{i}}\left(d_{n}\right)\right) \\
\vdots & \vdots & \ddots & \vdots \\
\left(\mu_{\delta_{m}}\left(d_{1}\right), \gamma_{\delta_{m}}\left(d_{1}\right), \pi_{\delta_{m}}\left(d_{1}\right)\right) & \left(\mu_{\delta_{m}}\left(d_{2}\right), \gamma_{\delta_{m}}\left(d_{2}\right), \pi_{\delta_{m}}\left(d_{2}\right)\right) & \cdots & \left(\mu_{\delta_{m}}\left(d_{n}\right), \gamma_{\delta_{m}}\left(d_{n}\right), \pi_{\delta_{m}}\left(d_{n}\right)\right)
\end{array}\right]
$$

Step 9. Calculate IF average alternative.

The IF average alternative of each DG is calculated as follows:

$$
\widetilde{A V}_{i j}{ }^{(g)}=\frac{\sum_{i=1}^{m} D_{i j}{ }^{(g)}}{n}=\frac{1}{n} \sum_{i=1}^{m} \mu_{i j}{ }^{(g)}, \frac{1}{n} \sum_{i=1}^{m} \gamma_{i j}{ }^{(g)}, \frac{1}{n} \sum_{i=1}^{m} \pi_{i j}{ }^{(g)}
$$

Where $j=1,2, \ldots, n$ and $g=1,2, \ldots, l$.

Step 10. Calculate PDA and NDA.

Hereby, the matrices of positive distance from average (PDA), and negative distance from average (NDA) are calculated using high accuracy values, calculated by Eq. (26), of intuitionistic fuzzy aggregated decision matrix and intuitionistic fuzzy average solution, according to the type of criteria as follows:

For beneficial criteria: $\quad P D A_{j}=\frac{\max \left(0,\left(\mathrm{~F}\left(D_{i j}{ }^{(g)}\right)-\mathrm{F}\left(\widetilde{A V}_{i j}{ }^{(g)}\right)\right)\right.}{F\left(\widetilde{A V}_{i j}{ }^{(g)}\right)}, \mathrm{g}=1,2, \ldots, 1$

For non-beneficial criteria: $\quad N D A_{j}=\frac{\max \left(0,\left(F\left(\widetilde{A V}_{i j}{ }^{(g)}\right)-\mathrm{F}\left(D_{i j}{ }^{(g)}\right)\right)\right.}{F\left(\widetilde{A V}_{i j}{ }^{(g)}\right)}, \mathrm{g}=1,2, \ldots, 1$

Step 11. Calculate NWPDA and NWNDA.

After the IFPDA and IFNDA are calculated, the high accuracy function of alternatives assessments is determine as explained in Step 7. Then, NWPDA and NWNDA are defined as follows:

$$
\begin{gathered}
N W P D A_{j}=\frac{\sum_{j=1}^{n}\left(F\left(w_{j}^{(g)}\right) * P D A_{j}\right)}{\max _{j}\left(F\left(w_{j}^{(g)}\right) * P D A_{j}\right)}, \quad \mathrm{g}=1,2, \ldots, 1 \\
N W N D A_{j}=1-\frac{\sum_{j=1}^{n}\left(F\left(w_{j}^{(g)}\right) * N D A_{j}\right)}{\max _{j}\left(F\left(w_{j}^{(g)}\right) * N D A_{j}\right)}, \quad \mathrm{g}=1,2, \ldots, 1
\end{gathered}
$$

Step 12. Calculate reference determination.

Hereby, the grey relational analysis starts. Reference determination is defined by assessing the ideal solution (IS) and anti-ideal (AIS) solution. The IS is introduced as:

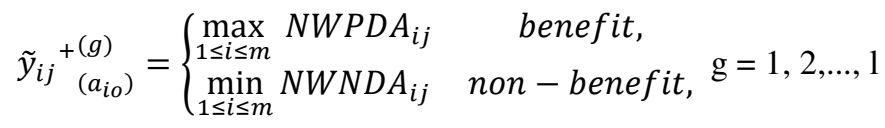

Similarly, AIS is depicted as follows:

$$
\tilde{y}_{i j} \underset{\left(a_{i o}\right)}{-(g)}=\left\{\begin{array}{l}
\min _{1 \leq i \leq m} N W N D A_{i j} \quad \text { benefit, } \\
\max _{1 \leq i \leq m} N W P D A_{i j} \quad \text { non - benefit, }
\end{array} \mathrm{g}=1,2, \ldots, 1\right.
$$

Step 13. Calculate grey relational coefficient.

Using square of difference, grey relational coefficient of each alternative from the IS is calculated as: 


$$
\begin{aligned}
& \tau_{i j}^{+(g)}=\frac{\min _{1 \leq i \leq m} \min _{1 \leq j \leq n}\left(\sqrt{\left(N W P D A\left(x_{j}\right)-\tilde{y}_{i j}{ }_{\left(a_{i o}\right)}^{(g)}\right)^{2}}\right)+\rho \max _{1 \leq i \leq m} \max _{1 \leq j \leq n}\left(\sqrt{\left(N W P D A\left(x_{j}\right)-\tilde{y}_{i j}{ }_{\left(a_{i o}\right.}^{(g)}\right)^{2}}\right)}{\left(\sqrt{\left(N W P D A\left(x_{j}\right)-\tilde{y}_{i j}{ }_{\left(a_{i o}\right)}^{(g)}\right)^{2}}\right)+\rho \max _{1 \leq i \leq m} \max _{1 \leq j \leq n}\left(\sqrt{\left(N W P D A\left(x_{j}\right)-\tilde{y}_{i j}{ }_{\left(a_{i o}\right)}^{(g)}\right)^{2}}\right)} \\
& i=1,2, \ldots, m \quad j=1,2, \ldots, n \quad g=1,2, \ldots, l
\end{aligned}
$$

Furthermore, grey relational coefficient of each alternative from the AIS is calculated as:

$$
\begin{aligned}
& {\tau_{i j}^{-}}^{-(g)}=\frac{\min _{1 \leq i \leq m} \min _{1 \leq j \leq n}\left(\sqrt{\left(N W N D A\left(x_{j}\right)-\tilde{y}_{i j}{ }_{\left(a_{i o}\right)}^{-(g)}\right)^{2}}\right)+\rho \max _{1 \leq i \leq m} \max _{1 \leq j \leq n}\left(\sqrt{\left(N W N D A\left(x_{j}\right)-\tilde{y}_{i j}{ }_{\left(a_{i o}\right)}^{-(g)}\right)^{2}}\right)}{\left(\sqrt{\left(N W N D A\left(x_{j}\right)-\tilde{y}_{i j}^{-(g)}{ }_{\left(a_{i o}\right)}\right)^{2}}\right)+\rho \max _{1 \leq i \leq m} \max _{1 \leq j \leq n}\left(\sqrt{\left(N W N D A\left(x_{j}\right)-\tilde{y}_{i j}{ }_{\left(a_{i o}\right)}^{-(g)}\right)^{2}}\right)} \\
& i=1,2, \ldots, m \quad j=1,2, \ldots, n \quad g=1,2, \ldots, l
\end{aligned}
$$

In (42) and (43), $\rho$ is identification coefficient and it can be adjusted so the better difference between series of $\tau_{i j}^{+(g)}$ and $\tau_{i j}^{-(g)}$ to $\tilde{y}_{i j}{ }_{\left(a_{i o}\right)}^{(g)}$ and $\tilde{y}_{i j}{ }_{\left(a_{i o}\right)}^{-(g)}$, respectively, can be achieved. It has a range of $\rho \in[0,1]$, and the smaller its value is, the larger is GRC. Usually, $\rho=0.5$ is applied because it offers moderate distinguishing effect and stability (Lin, Lu and Lewis, 2007). Changing the value of $\rho$ will only change the magnitude of the relational coefficient but it does not affect the rank of the GRD (Chiang, Tsai and Wang, 2002).

Step 14. Determine GRD: ranking by each DG.

In this step, the ranking of each DG is provided calculating the GRD as shown below:

$$
\tau_{i j}^{(g)}=\frac{\tau_{i j}^{+(g)}}{{\tau_{i j}^{+(g)}+\tau_{i j}^{(g)}}^{(g)}}, \quad i=1,2, \ldots, m, j=1,2, \ldots, n .
$$

The alternative with the higher $\tau_{i j}{ }^{(g)}$ is considered the optimal then others and ranked higher.

Step 15. Defining the goal function and constrains.

Final common ranking can be achieved by gathering together all DGs and asking them to make decision conventionally, otherwise, common ranking is determined using numerical simulation by Integer Linear Programing based on Ant Colony Optimization (ILP-ACO) as authors proposed. Taking into the account strategy of SDC, remediation is planned to be implemented through one investment cycle (four years). Firstly, the goal function and constraints are determined for each DG as follows:

$$
\begin{aligned}
& \max \sum_{i=1}^{n} \tau_{i} x_{i} \\
& \text { s.t. }\left\{\begin{array}{l}
\sum x_{i} \sim a_{i} \\
\sum m x_{i} \leq b_{i} \\
\sum_{i} f x_{i} \leq c_{i} \\
x_{i} \in\{0,1\} \\
i=1,2, \ldots, n
\end{array}\right.
\end{aligned}
$$

where $\tau_{i}$ is GRD obtained in previous step, $\sim$ holds for $=,<$ or $>, a_{i}, b_{i}$ and $c_{i}$ are spatial-functional, time and financial constraints, respectively. $m$ are months needed for the remediation of each bridge, and $f$ is an estimated budget for remediation of each bridge. $x_{i}$ denote bridges. For each year of planned investment cycle for the remediation, the set of bridges for each DG is defined.

Step 16. Definition of the common set of bridges. 
The common set of bridges is determined using ACO simulation as follows:

$$
\Delta \vartheta_{i j}^{k}=\left\{\begin{array}{lr}
\frac{1}{L_{k}}, & k^{t h} D G \text { path on the bridge } i, j \\
0 & \text { otherwise }
\end{array}\right.
$$

Where $\Delta \vartheta$ is the value of how many times the path from bridge $i$, to bridge $j$ is repeated, where $k$ is the $k^{\text {th }}$ DG. If the path does not lead to a bridge, it is equal to 0 , otherwise, it is equal to $\frac{1}{L_{k}}$. $L_{k}$ is the level of path by the $k^{t h}$ DG. The amount of total length of each path is calculated by summing all lengths between bridges, as given:

$$
\vartheta_{i j}^{k}=\sum_{k=1}^{m} \Delta \vartheta_{i j}^{k}
$$

Where $m$ is the total number of DGs.

The selected path needs to be the shortest one. To choose the right path the probability is calculated as follows:

Where $\varphi_{i, j}=\frac{1}{L_{i, j}}$, and $\alpha, \beta=1$.

$$
P_{i, j}=\frac{\left(\vartheta_{i, j}\right)^{\alpha}\left(\varphi_{i, j}\right)^{\beta}}{\sum\left(\left(\vartheta_{i, j}\right)^{\alpha}\left(\varphi_{i, j}\right)^{\beta}\right)}
$$

Step 17. Final common ranking of the bridges.

Common ranking is defined by the set of bridges determined for each year of the investment circle. 


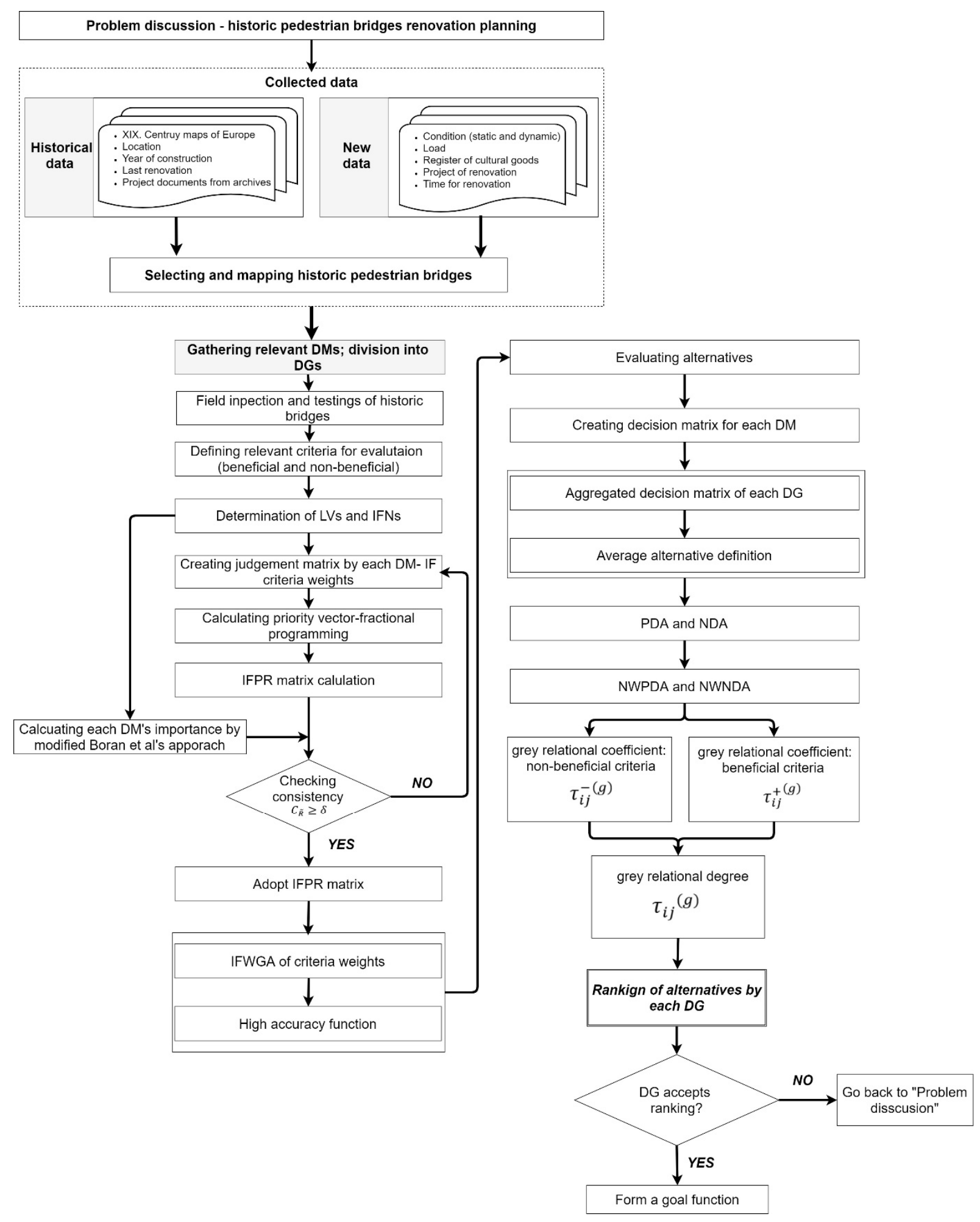

Fig. 1. DS model: priority ranking of bridges by each DG (steps 1-14). 


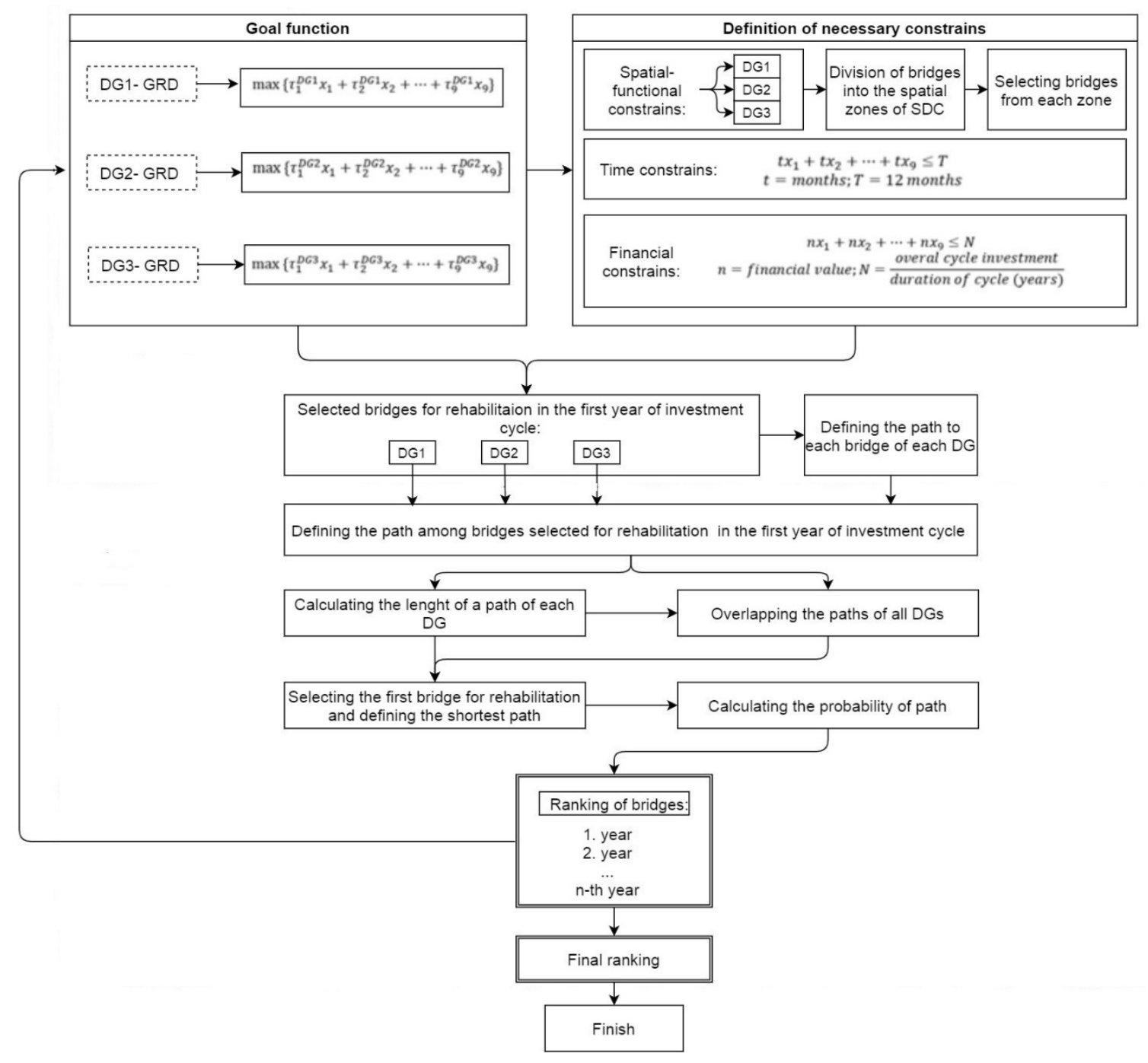

Fig. 2. DS model: final priority ranking of bridges (steps 15-17).

\section{Numerical illustration of DS model}

The list of historic bridges built during the end of Austro-Hungarian Monarchy in the area of SDC is established by (Rogulj et al, 2019). Among them are pedestrian bridges, evaluated in this study. Conservative department in Split (Ministry of Culture), Croatia is managing pedestrian bridges that belong to cultural heritage of SDC. According to the extensive and detailed inspection made by structural and conservative experts, these bridges need to be subjected to construction and architectural activity, such is remediation, to sustain their load capacity, durability and functionality. Three DGs of experts are formed to assess the alternatives: (DG1) civil engineers and architects, (DG2) conservatives, and (DG3) economists. Nine alternatives are generated and the most indispensable for the remediation will be the one with the highest calculated GRD value. These alternatives are: $\left(A_{1}\right)$ Kastilac, Kastel Gomilica; $\left(\mathrm{A}_{2}\right)$ Ricevica, Kastel Stafilic; $\left(\mathrm{A}_{3}\right)$ The bridge next to the Castel Vitturi, Kastel Luksic; $\left(\mathrm{A}_{4}\right)$ The bridge next to the Cosic mill, Grab; $\left(A_{5}\right)$ The bridge next to the Samardic mill, Grab; $\left(A_{6}\right)$ Small bridge over river Grab, Grab; $\left(\mathrm{A}_{7}\right)$ Gorucica, Sinj; $\left(\mathrm{A}_{8}\right)$ Vrboska, Hvar; $\left(\mathrm{A}_{9}\right)$ Franjo Josip, Brac. Also, the same three interactive DGs are asked to establish criteria. Generated criteria are given with their beneficial/non-beneficial determination as follows:

(C1) Safety and stability (non-beneficial) - represents safety that meets the standards (Eurocodes) for bridges, mechanical resistance and stability, and seismic safety.

(C2) Complexity of reconstruction (non-beneficial) - represents the complexity of project design, static calculation, complexity of reconstruction design and capacity of the whole structure.

(C3) Load (beneficial) - represents the capacity of the people, and for some bridges a load of vehicles they can bear. 
(C4) Cost (non-beneficial) - it is related to the reduction of the project and reconstruction cost, from project design to the reconstruction activates and disposal of the waste material.

(C5) Functionality (non-beneficial) - it is related to the traffic quality and forming of a suitable structural reply to the inflict deformations throughout the bridge functioning phase.

(C6) Environmental impact (non-beneficial) - it is linked to the protection of environment and surrounding landscape from the reconstruction activities and the impact of the used materials.

(C7) Reconstruction duration (non-beneficial) - presents the predicted time for the reconstruction, from assembling required mechanical equipment to the finishing works and waste material disposal. which needs to be minimized.

(C8) Preservation of cultural heritage (beneficial) - it is related to the preservation of the original appearance and aesthetics of the bridge, all within the laws and regulations of the Ministry of Culture.

Three DGs are formed and they have seven, four and three members, respectively. The first decision group (DG1) contains seven, the second decision group (DG2) has four, and the third (DG3) has three decision maker. To each member of each group, importance is given according to his/her years of experience in the field of historical civil and structural construction and conservative management. In Table 1 detailed list of linguistic values (LVs) for DMs' importance is presented and their transformation to IFNs (the same LVs and IFNs are used for the criteria weights).

Table 1

LVs and IFNs for criteria weights.

\begin{tabular}{cc}
\hline LVs & IFNs \\
\hline Extreme unimportant (EU) & $(0.05,0.95,0.00)$ \\
\hline Very very unimportant (VVU) & $(0.10,0.90,0.00)$ \\
\hline Very unimportant (VU) & $(0.15,0.80,0.05)$ \\
\hline Unimportant (U) & $(0.30,0.65,0.05)$ \\
\hline Medium (M) & $(0.50,0.50,0.00)$ \\
\hline Important (I) & $(0.65,0.30,0.10)$ \\
\hline Very important (VI) & $(0.80,0.15,0.05)$ \\
\hline Very very important (VVI) & $(0.90,0.10,0.00)$ \\
\hline Extreme important (EI) & $(0.95,0.05,0.00)$ \\
\hline
\end{tabular}

To obtain the importance of the DMs, (8) is used. The calculated values of importance of $\lambda$ for each member of each group are given in Table 2.

Table 2

Assigned linguistic values and calculated importance of each DG's member.

\begin{tabular}{llllllll}
\hline DG1 & DM1 & DM2 & DM3 & DM4 & DM5 & DM6 & DM7 \\
\hline$\lambda$ & 0.19 & 0.17 & 0.17 & 0.13 & 0.13 & 0.10 & 0.10 \\
\hline DG2 & DM1 & DM2 & DM3 & DM4 & & & \\
\hline$\lambda$ & 0.30 & 0.27 & 0.23 & 0.20 & & \\
\hline DG3 & DM1 & DM2 & DM3 & & & \\
\hline$\lambda$ & 0.38 & 0.33 & 0.29 & & & \\
\hline
\end{tabular}

Furthermore, each DM defined criteria weights using LVs from Table 1, and thus, intuitionistic fuzzy judgement matrices are formed. Using model of fractional programming defined by Eq. (13), the priority vectors are defined. Then, IFPR matrix with intuitionistic fuzzy criteria weights are calculated for each DM and the consistency is checked. Matrices which were not consistent $(C R<0.90)$, decision makers were asked to redefined criteria weights. After the consistency is achieved for all DM's criteria weights, IFWGA is used to calculate aggregated matrix for each DG. In Table 3, priority vector and consistency ratio are given for each DM.

Table 3

Priority vector for each DM and consistency ratio.

\begin{tabular}{|c|c|c|c|c|c|c|c|c|c|c|c|}
\hline & & & $\mathrm{C} 1$ & $\mathrm{C} 2$ & C3 & $\mathrm{C} 4$ & C5 & C6 & C7 & $\mathrm{C} 8$ & $\mathrm{CR}$ \\
\hline \multirow{10}{*}{ DG1 } & \multirow{2}{*}{ DM1 } & $\mu$ & 0.63 & 0.49 & 0.57 & 0.24 & 0.16 & 0.42 & 0.26 & 0.31 & \multirow{2}{*}{0.90} \\
\hline & & $\gamma$ & 0.16 & 0.51 & 0.28 & 0.62 & 0.73 & 0.56 & 0.73 & 0.69 & \\
\hline & \multirow{2}{*}{ DM2 } & $\mu$ & 0.72 & 0.23 & 0.62 & 0.06 & 0.03 & 0.31 & 0.09 & 0.13 & \multirow{2}{*}{0.92} \\
\hline & & $\gamma$ & 0.12 & 0.77 & 0.25 & 0.92 & 0.96 & 0.61 & 0.90 & 0.86 & \\
\hline & \multirow{2}{*}{ DM3 } & $\mu$ & 0.58 & 0.36 & 0.54 & 0.17 & 0.14 & 0.27 & 0.18 & 0.18 & \multirow{2}{*}{0.92} \\
\hline & & $\gamma$ & 0.13 & 0.64 & 0.22 & 0.68 & 0.66 & 0.71 & 0.81 & 0.70 & \\
\hline & \multirow{2}{*}{ DM4 } & $\mu$ & 0.76 & 0.09 & 0.18 & 0.02 & 0.00 & 0.09 & 0.03 & 0.04 & \multirow{2}{*}{0.90} \\
\hline & & $\gamma$ & 0.07 & 0.91 & 0.77 & 0.60 & 0.99 & 0.88 & 0.97 & 0.96 & \\
\hline & \multirow{2}{*}{ DM5 } & $\mu$ & 0.76 & 0.26 & 0.52 & 0.09 & 0.07 & 0.26 & 0.13 & 0.17 & \multirow{2}{*}{0.94} \\
\hline & & $\gamma$ & 0.11 & 0.74 & 0.31 & 0.85 & 0.85 & 0.73 & 0.78 & 0.82 & \\
\hline
\end{tabular}




\begin{tabular}{|c|c|c|c|c|c|c|c|c|c|c|c|}
\hline & \multirow{2}{*}{ DM6 } & $\mu$ & 0.67 & 0.35 & 0.59 & 0.17 & 0.13 & 0.34 & 0.17 & 0.34 & \multirow{2}{*}{0.95} \\
\hline & & $\gamma$ & 0.13 & 0.65 & 0.33 & 0.75 & 0.71 & 0.64 & 0.71 & 0.64 & \\
\hline & \multirow{2}{*}{ DM7 } & $\mu$ & 0.75 & 0.44 & 0.40 & 0.18 & 0.22 & 0.38 & 0.21 & 0.19 & \multirow{2}{*}{0.93} \\
\hline & & $\gamma$ & 0.13 & 0.56 & 0.51 & 0.72 & 0.64 & 0.55 & 0.68 & 0.74 & \\
\hline \multirow{8}{*}{ DG2 } & \multirow{2}{*}{ DM1 } & $\mu$ & 0.82 & 0.44 & 0.44 & 0.17 & 0.29 & 0.17 & 0.22 & 0.12 & \multirow{2}{*}{0.93} \\
\hline & & $\gamma$ & 0.06 & 0.56 & 0.56 & 0.59 & 0.71 & 0.59 & 0.64 & 0.75 & \\
\hline & \multirow{2}{*}{ DM2 } & $\mu$ & 0.67 & 0.57 & 0.55 & 0.28 & 0.18 & 0.16 & 0.16 & 0.28 & \multirow{2}{*}{0.91} \\
\hline & & $\gamma$ & 0.16 & 0.43 & 0.41 & 0.56 & 0.69 & 0.67 & 0.67 & 0.52 & \\
\hline & \multirow{2}{*}{ DM3 } & $\mu$ & 0.64 & 0.35 & 0.63 & 0.31 & 0.17 & 0.21 & 0.32 & 0.35 & \multirow{2}{*}{0.94} \\
\hline & & $\gamma$ & 0.20 & 0.65 & 0.23 & 0.62 & 0.71 & 0.51 & 0.62 & 0.65 & \\
\hline & \multirow{2}{*}{ DM4 } & $\mu$ & 0.65 & 0.50 & 0.50 & 0.17 & 0.13 & 0.33 & 0.17 & 0.32 & \multirow{2}{*}{0.91} \\
\hline & & $\gamma$ & 0.12 & 0.50 & 0.40 & 0.73 & 0.70 & 0.66 & 0.73 & 0.64 & \\
\hline \multirow{6}{*}{ DG3 } & \multirow{2}{*}{ DM1 } & $\mu$ & 0.67 & 0.56 & 0.56 & 0.36 & 0.35 & 0.27 & 0.18 & 0.18 & \multirow{2}{*}{0.93} \\
\hline & & $\gamma$ & 0.16 & 0.44 & 0.44 & 0.63 & 0.64 & 0.56 & 0.71 & 0.70 & \\
\hline & \multirow{2}{*}{ DM2 } & $\mu$ & 0.72 & 0.31 & 0.36 & 0.57 & 0.20 & 0.20 & 0.08 & 0.04 & \multirow{2}{*}{0.92} \\
\hline & & $\gamma$ & 0.07 & 0.69 & 0.51 & 0.21 & 0.78 & 0.78 & 0.92 & 0.90 & \\
\hline & \multirow{2}{*}{ DM3 } & $\mu$ & 0.67 & 0.51 & 0.17 & 0.17 & 0.34 & 0.34 & 0.34 & 0.26 & \multirow{2}{*}{0.90} \\
\hline & & $\gamma$ & 0.12 & 0.49 & 0.73 & 0.73 & 0.66 & 0.66 & 0.66 & 0.57 & \\
\hline
\end{tabular}

Furthermore, high accuracy function $(F)$ values are calculated by Eq. (26) to obtain defuzified criteria weights. These defuzified criteria weights are then normalized as presented in Table 4. It is obvious that the stability and functionality of the bridge is the most important for all groups.

Table 4

Normalized defuzified values of criteria weights.

\begin{tabular}{cccc}
\hline & DG1 & DG2 & DG3 \\
\hline C1 & 0.19 & 0.19 & 0.18 \\
\hline C2 & 0.16 & 0.18 & 0.18 \\
\hline C4 & 0.17 & 0.19 & 0.12 \\
\hline C5 & 0.04 & 0.07 & 0.13 \\
\hline C6 & 0.10 & 0.10 & 0.15 \\
\hline C8 & 0.16 & 0.09 & 0.13 \\
\hline
\end{tabular}

All alternatives are evaluated by each DM. The evaluations are given using LVs and their belonging IFNs as presented in Table 5 .

Table 5

LVs and IFNs for the alternative assessment.

\begin{tabular}{cc}
\hline LVs & IFNs \\
\hline Extreme poor (EP)/Extreme low (EL) & $(0.05,0.95,0.00)$ \\
\hline Very poor (VP)/Very low (VL) & $(0.15,0.80,0.05)$ \\
\hline Poor (P)/Low (L) & $(0.25,0.65,0.10)$ \\
\hline Medium poor (MP)/Medium low (ML) & $(0.35,0.55,0.10)$ \\
\hline Medium (M)/Fair (F) & $(0.40,0.45,0.15)$ \\
\hline Medium good (MG)/Medium high (MH) & $(0.55,0.35,0.10)$ \\
\hline Good (G)/High (H) & $(0.65,0.25,0.10)$ \\
\hline Very good (VG)/Very high (VH) & $(0.80,0.15,0.05)$ \\
\hline Extreme good (EG)/Extreme high (EH) & $(0.95,0.05,0.00)$ \\
\hline
\end{tabular}

The assessments of alternatives by each DM are aggregated into the DG's common opinion. For each alternative, membership, non-membership, and hesitation degree are calculated. These degrees present how much each alternative belongs to the highest level of assessment EG/EH by each criterion. Meaning, the alternative with the lowest membership degree, the highest non-membership degree, and minimum hesitation, the least is near to the $\mathrm{EG} / \mathrm{EH}$ level, and this alternative is considered the most necessary when it comes to the remediation of the bridges. This statement is especially important for the assessment by criteria $\mathrm{C} 1$ and $\mathrm{C} 3$, where for a bridge near EG/EH level, remediation is not necessary. Criterion C2 "binds" to the criterion $\mathrm{C} 1$, meaning, bridge with the low safety and stability often demands more complex remediation, hence, bridges with higher complexity of remediation have higher priority for the remediation. The same can be said for the criterion C3. Bridges with a higher load can cause higher stress and thus greater damage. For that reason, bridges that have membership degrees near EG/EH level according to the criterion $\mathrm{C} 3$, are considered more important for the remediation. In this case, bridges do not suffer high dynamical loads, because there are mostly situated in the inner part of SDC where the pedestrian load is very low. Furthermore, with criteria C4-C7, the situation is a little bit different. Namely, DMs preferred more bridges with lower financial expenses and time duration of reconstruction. Hence, bridges that are closer to the EP/EL level by criteria C4-C7 are more preferable. Criterion C8 presents the preservation of cultural heritage, 
therefore, a bridge that is closer to the $\mathrm{EG} / \mathrm{EH}$, by this criterion is considered more necessary for the remediation. Although, all bridges should be equally important by this criterion, current safety and stability of a bridge greatly influence the final decision of the DMs. Form this claim, it is obvious that the importance of criterion $\mathrm{C} 1$ has the most significant role in defining final ranking. According to the aggregated assessments of bridges, it is clear that A1 bridge has the lowest membership by criterion $\mathrm{C} 1$ for all three DGs. The highest membership degree according to $\mathrm{C} 1$ has $\mathrm{A} 2$, A4, and $\mathrm{A} 5$ by DG1, A3 and A4 by DG2, and A3, A5, A6, and A7 by DG3. Although these bridges have the highest values for $\mathrm{C} 1$, their safety and stability are still not satisfying and reconstruction is needed but it is not necessary as it is for A1. Furthermore, Figures 3-8 present membership and non-membership degree of each alternative by each DG. Also the average alternative (AA) is presented which is further used for calculation of NWPDA and NWNDA of each DG. NWPDA and NWNDA are shown in Fugures 9 and 10, respectively.

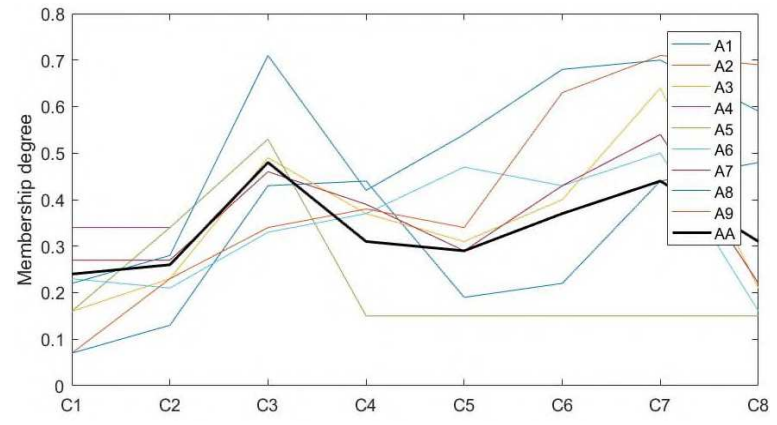

Fig. 3. DG1 membership degree for AA

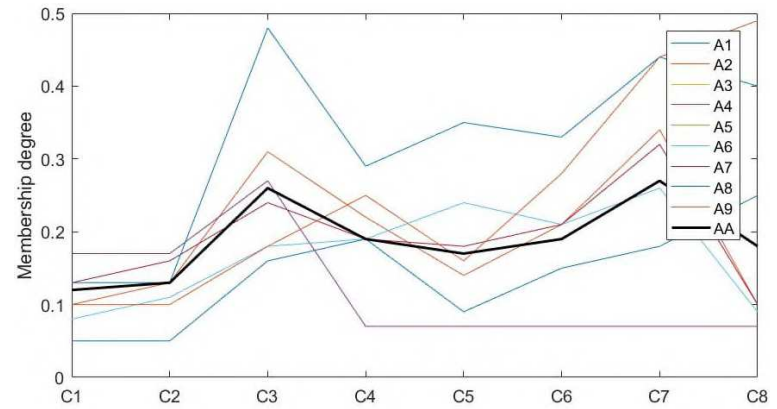

Fig. 5. DG2 membership degree for AA

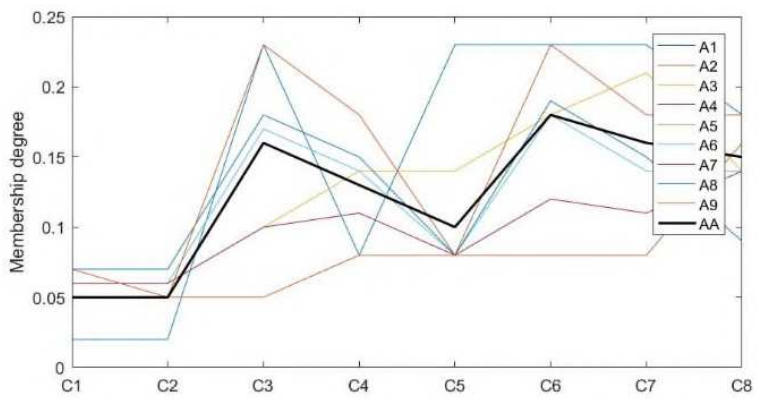

Fig. 7. DG3 membership degree for AA

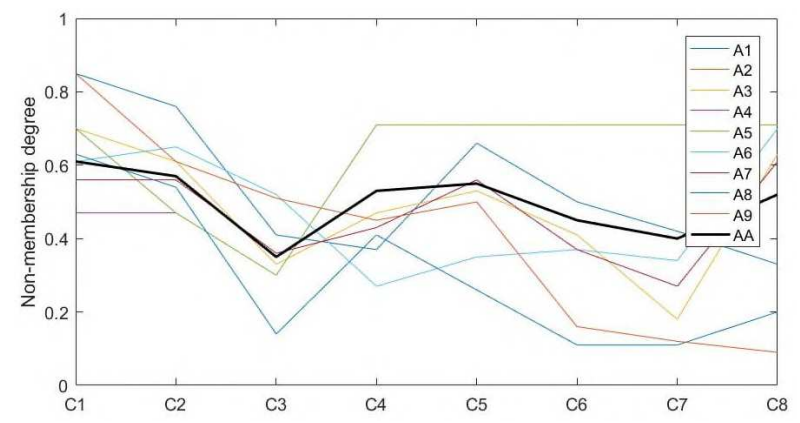

Fig. 4. DG1 non-membership degree for AA

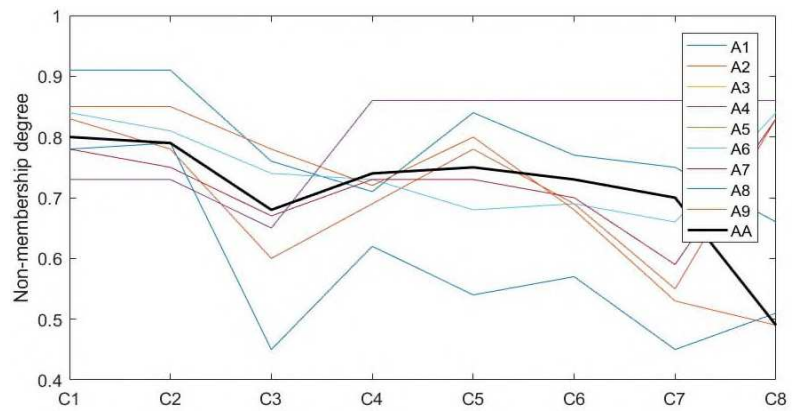

Fig. 6. DG2 non-membership degree for AA

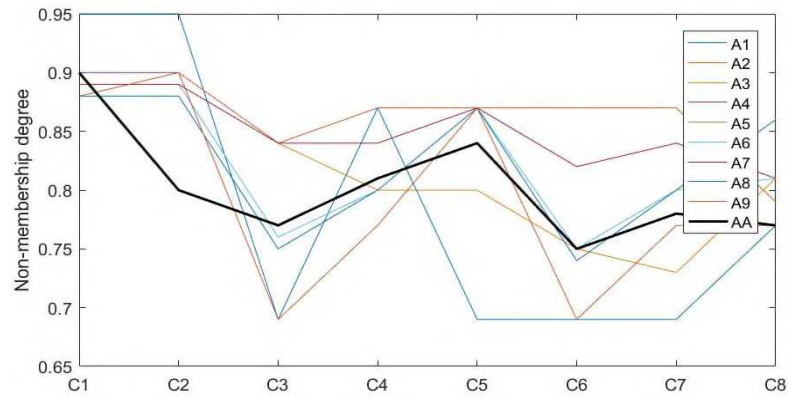

Fig. 8. DG3 non-membership degree for AA 


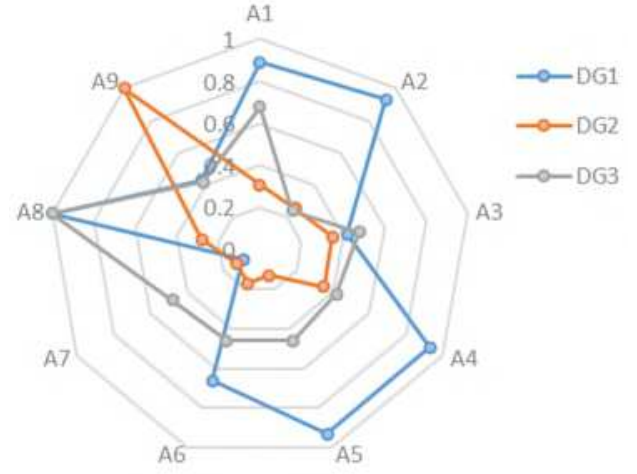

Fig. 9. NWPDA for each DG.

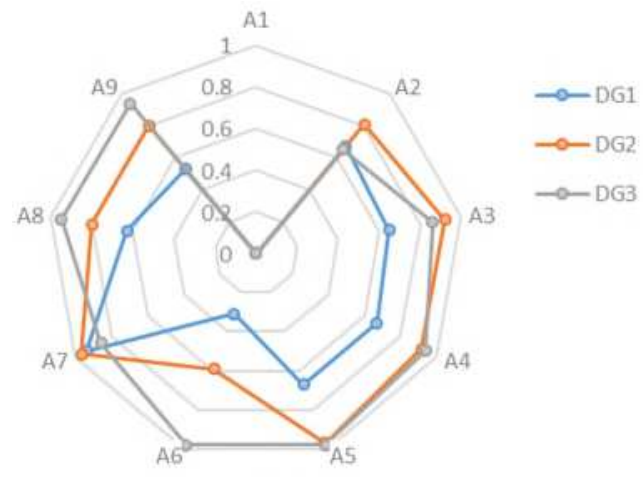

Fig. 10. NWNDA for each DG.

Furthermore, the GRCs for beneficial and non-beneficial criteria are calculated, as well as GRD for each group. The GRD values and final ranking by each DG are presented in Figure 11. The alternatives with the highest GRD are considered more prioritized for the remediation.

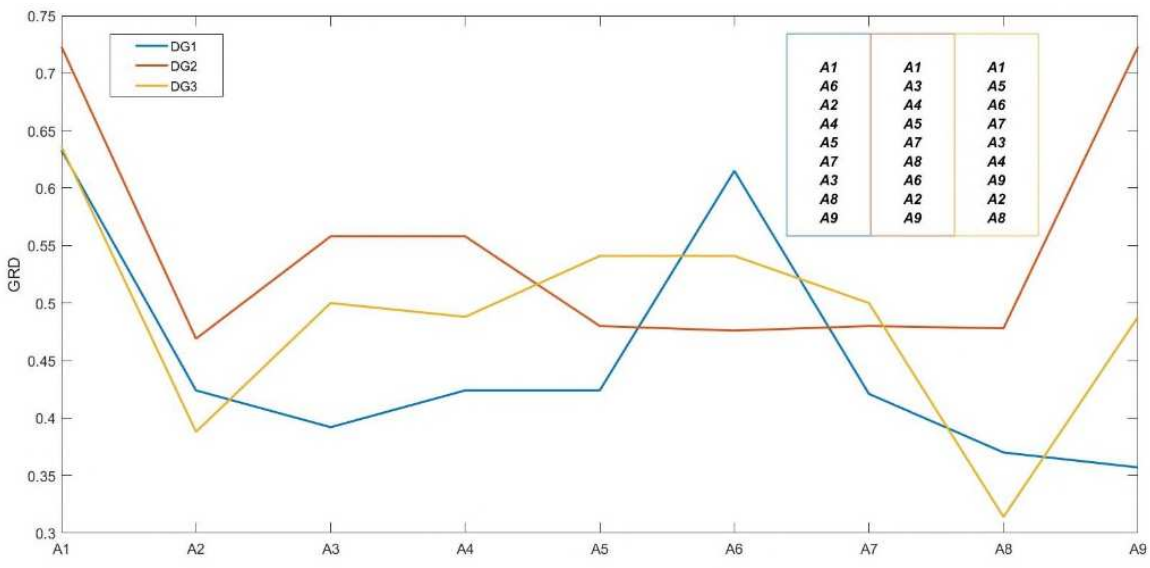

Fig. 11. GRD and final ranking for each DG.

Furthermore, after the definition of ranking by each DG, it is necessary to determine final common ranking. The ILP is used to defined set of bridges for remediation for each investment year. The goal function is defined using GRD values and constrains as explained in (45) and Figure 2. Spatial-functional constrains, given in Table 6, are defined according to spatial distribution of bridges, and by this analogy A1, A2, and A3 are in the first zone (town of Kastela), A4, A5, and A6 are in the second zone (town of Grab), A7 in the third zone (town of Sinj), and A8 and A9 are in the fourth zone (islands Brac and Hvar). Time constrain are defined by the duration of each bridge remediation within each year of investment cycle, and the financial constrain are determined by cost of remediation in monetary unit. Time and financial constrains for the simplicity are taken as equal for each DG.

Goal function for each DG:

DG1: $\max \left\{0.633 x_{1}+0.424 x_{2}+0.392 x_{3}+0.424 x_{4}+0.424 x_{5}+0.615 x_{6}+0.421 x_{7}+0.370 x_{8}+0.357 x_{9}\right\}$

DG2: $\max \left\{0.723 x_{1}+0.469 x_{2}+0.558 x_{3}+0.558 x_{4}+0.480 x_{5}+0.476 x_{6}+0.480 x_{7}+0.478 x_{8}+0.262 x_{9}\right\}$

DG3: $\max \left\{0.636 x_{1}+0.388 x_{2}+0.500 x_{3}+0.488 x_{4}+0.541 x_{5}+0.541 x_{6}+0.500 x_{7}+0.314 x_{8}+0.488 x_{9}\right\}$

Table 6

Spatial-functional constrains:

\begin{tabular}{lccc}
\hline & DG1 & DG2 & DG3 \\
\hline Zone 1 & $x_{1}+x_{2}+x_{3} \geq 2$ & $x_{1}+x_{2}+x_{3} \geq 1$ & $x_{1}+x_{2}+x_{3} \geq 1$ \\
\hline Zone 2 & $x_{3}+x_{4}+x_{5} \geq 1$ & $x_{3}+x_{4}+x_{5} \geq 1$ & $x_{3}+x_{4}+x_{5} \geq 1$ \\
\hline Zone 3 & $x_{7} \leq 1$ & $x_{7} \leq 1$ & $x_{7} \geq 0$ \\
\hline Zone 4 & $x_{8}+x_{9}=1$ & $x_{8}+x_{9}=1$ & $x_{8}+x_{9}=1$ \\
\hline
\end{tabular}

Time constrain: $8 x_{1}+2 x_{2}+3 x_{3}+7 x_{4}+6 x_{5}+3 x_{6}+3 x_{7}+4 x_{8}+7 x_{9} \leq 12$

Financial constrains: $30 x_{1}+5 x_{2}+5 x_{3}+20 x_{4}+10 x_{5}+5 x_{6}+5 x_{7}+15 x_{8}+20 x_{9} \leq 30$ 
For the first set of bridges only A1 is chosen to be reconstructed in the first year as this bridge is the most deteriorated and is a priority by each DG. The set of bridges for remediation in the second year of investment cycle is obtained as follows: for DG, A2, A3, A6 and A8, and for DG2 and DG3 is A2, A6 and A8. These sets are simulated by ACO to provide a common ranking of bridges for the first investment year.

Bridges are positioned in a nine-polygons, as presented in Figure 11, one polygon for each group. Connections inside polygons (red, green and blue) are paths. These paths represent the ranking of first set, starting from the bridge with the highest GRD and ending with the smallest. Between each bridge, the length of path is measured.
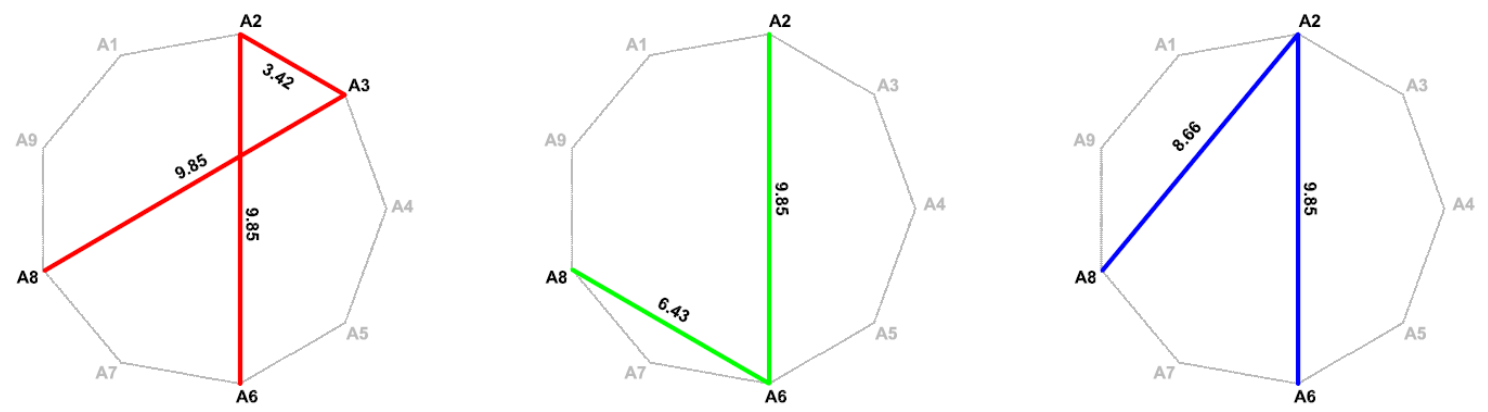

Fig. 11. Nine- polygons for DG1 (red path), DG2 (green path) and DG3 (blue path).

The length of each path is calculated as follows:

$L_{D G 1}=23.12 \rightarrow \Delta \vartheta_{i, j}{ }^{D G 1}=\frac{1}{23.12}=0.043 ; L_{D G 2}=16.28 \rightarrow \Delta \vartheta_{i, j}{ }^{D G 2}=\frac{1}{16.28}=0.061 ; L_{D G 3}=18.51 \rightarrow$ $\Delta \vartheta_{i, j}^{D G 3}=\frac{1}{18.51}=0.054$

The overlap of all paths shows the amount of pheromones on each length of each path, as presented in Figure 12.

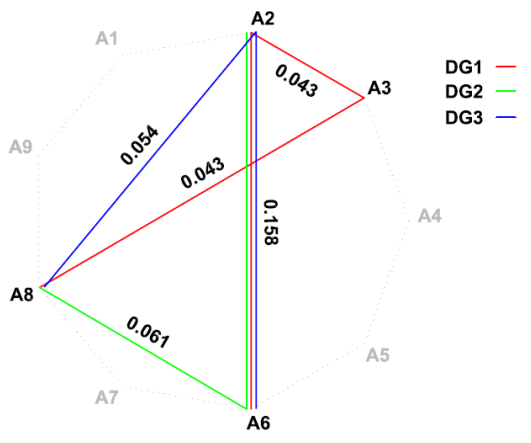

Fig. 12. Overlapped paths.

Calculating the probability, the direction of each path is determined from the common source, A6, which has the highest GRD for DG1 and DG3. From the Figure 12 it is obvious that path leads from A6 to A2 with the probability $P_{(A 6 \rightarrow A 2)}=82.98 \%$. Following the length between bridges, the ranking for the second set is defined as: $A 6>$ $A 2>A 8>A 3$. Same procedure is repeated for the third and fourth set with the exclusion of the bridges from previous sets. Final common ranking of bridges within each year is obtained as follows:

$1^{\text {st }}$ year: $A 1 ; 2^{\text {nd }}$ year: $A 6>A 2>A 8>A 3 ; 3^{\text {rd }}$ year: $A 4>A 7 ; 4^{\text {th }}$ year: $A 5$; next investment cycle, $1^{\text {st }}$ year: $A 9$.

\section{Discussion}

\subsection{Sensitivity analysis-stability intervals}

To examine how modifying the weights of criteria affect final ranking of historic pedestrian bridges, the stability intervals are used to calculate the upper and lower values of initial criteria weights. The values of high accuracy function of criteria weights calculated by (26) are used as initial to determine lower and upper weights of interval. Within these intervals, the obtained final ranking of each DG remains unchanged, which confirms the stability of the given weights. In Table 7, intervals of criteria weights for each group are presented.

Different sets of criteria weights are applied to the defined case study to check the stability of obtained rankings. In this case, only the final ranking of each group is checked on sensitivity, assuming that it also affects the final common ranking. These sets of criteria weights are defined for eight criteria. Weights $w_{i}$ are used to express the relative importance of diverse criteria. The stability intervals of criteria weights are demonstrated by Mareschal (1988), who proposed a process for sensitivity analysis that introduces stability intervals. The weight values of one criterion inside the stability interval do not change the results from the preliminary set of weights. Using initial 
weights $w_{i}$ for each criterion, the weight stability interval $\left[w_{i}^{L}, w_{i}^{U}\right]$ is determine. The ranking of solutions obtained with initial weights will be modified if the weight value is out of the stability interval. The weight for the $i$ th criterion may increase or decrease from its initial value $w_{i}$, thus the changed weight can be described as $w_{i}^{\prime}=\alpha w_{i}$. To have the changed weights normalized, meaning $\sum_{k=1}^{n} w_{k}^{\prime}=1$, other weights are changed, keeping initially defined ratios: $w_{k}^{\prime}=\alpha w_{k}, k \neq i, k=1, \ldots, n$. The function $\tau(\alpha)$ is obtained from the expression $\alpha w_{i}+$ $\tau \sum_{k \neq i} w_{k}=1$ in the following form $\tau=\frac{\left(1-\alpha w_{i}\right)}{\left(1-w_{i}\right)}$. The parameter $\alpha$ can vary in the interval $0 \leq \alpha \leq \frac{1}{w_{i}}$. Applying EDAS method with different values of $\alpha$, the interval $\alpha_{1} \leq \alpha \leq \alpha_{2}$, can be achieved with initial weights, and this interval is stability interval. The weight stability interval can be defined as: $w_{i}^{L} \leq w_{i}^{\prime} \leq w_{i}^{U}$, where $w_{i}^{L}=\alpha_{1} w_{i}$, and $w_{i}^{U}=\alpha_{2} w_{i}$. Then the weight stability intervals are defined for each criterion, $i=1, \ldots, n$, with the values of the initial weights.

Table 7

Stability intervals of criteria weights for each DG.

\begin{tabular}{cccccccccc}
\hline & & DG1 & & & DG2 & \multicolumn{2}{c}{ DG3 } \\
\hline & $w$ & $w^{L}$ & $w^{U}$ & $w$ & $w^{L}$ & $w^{U}$ & $w^{L}$ & $w^{U}$ \\
\hline C1 & 0.19 & 0.18 & 0.21 & 0.19 & 0.17 & 0.21 & 0.18 & 0.16 \\
\hline C2 & 0.16 & 0.15 & 0.17 & 0.18 & 0.17 & 0.19 & 0.18 & 0.17 \\
\hline C3 & 0.17 & 0.17 & 0.17 & 0.19 & 0.18 & 0.21 & 0.12 & 0.11 \\
\hline C4 & 0.04 & 0.04 & 0.08 & 0.07 & 0.07 & 0.07 & 0.13 & 0.13 & 0.16 \\
\hline C5 & 0.10 & 0.05 & 0.16 & 0.10 & 0.10 & 0.20 & 0.15 & 0.14 \\
\hline C6 & 0.16 & 0.14 & 0.19 & 0.09 & 0.08 & 0.10 & 0.13 & 0.11 \\
\hline C7 & 0.08 & 0.08 & 0.09 & 0.07 & 0.06 & 0.08 & 0.08 & 0.07 \\
\hline C8 & 0.11 & 0.11 & 0.22 & 0.09 & 0.08 & 0.18 & 0.04 & 0.04 \\
\hline
\end{tabular}

For each DG, small deviations of stability intervals of the criteria weights are determined. Values of weights within these intervals keep obtained final rankings of each DG same as provided by initial weights.

\subsection{Comparison with other MCDM methods}

Hereby, the comparison of ranking results obtained by each DG with other MCDM methods under intuitionistic fuzzy environment such are TOPSIS (Memari et al, 2019) and VIKOR (Zeng, Chen, and Kuo, 2019) is presented. Table 8 shows results of priority ranking of the bridges for each group by the proposed method, IF TOPSIS and IF VIKOR. Also, the values of $\mathrm{R}$ and $\mathrm{Q}$ are given for better insight. For the IF TOPSIS method, the higher $\mathrm{R}$ value is, the more prior bridge is for the reconstruction, and for the IF VIKOR method, the lower the $Q$ value is, the higher is bridges positioned in the rank. Correlation of the rankings between proposed methodology and each of two methods is calculated by Spearman's rank correlation coefficient. Spearman's rank correlation coefficient, $r_{S} \in[-1,1]$, is statistical approach used to define the relationship strength between two different variables. To have higher correlation between proposed methodology and each method, $r_{s}$ needs to be greater than 0.8 .

The $r_{s}$ of proposed methodology is higher than 0.9 to both methods for all three groups. The highest correlation is shown to be for IF TOPSIS method for DG3, which is 0.983 . It is obvious that the ranking of proposed methodology is highly correlated with two MCDM methods. Hence, proposed method is very efficient.

Despite the high correlation, some shortcomings in the two methods are present. This primarily refers to the solutions on which each method is based. The IF TOPSIS and IF VIKOR are calculated taking into account ideal solutions, while IF EDAS GRD observes both ideal solutions and average solution. This way, the number of reference points is increased thus allowing an accurate and precise outcome. Namely, if we look at the obtained results of both methods, we can see the difference in the position of the bridge Kastilac, Kastel Gomilica (A1). For DG2 and DG3 it is positioned in second place for both methods, and for DG3 it is also positioned in second place according to IF VIKOR method. This takes away advantage for the reconstruction of the A1 bridge, which is the most dilapidated and whose stability and safety are the lowest. On the other hand, for DG3, according to both methods, the A9 bridge was not in the last place. This bridge is in good condition by all criteria and is the least prior for remediation. Small deviations can also be observed in other positions for both methods compared to the proposed method, however they are not so significant because what is more important is the first position in the ranking that should belong to bridge A1. Therefore, from all the above mentioned, it can be concluded that despite the validity of the methods IF TOPSIS and IF VIKOR, the proposed method IF EDAS GRD proved to be more efficient and accurate.

Table 8

Comparison with IF TOPSIS and IF VIKOR.

\begin{tabular}{cccccccc}
\hline & DG1 & & DG2 & & DG3 & IF EDAS \\
\hline \multirow{2}{*}{ IF TOPSIS } & \multirow{2}{*}{ IF VIKOR TOPSIS } & $\begin{array}{c}\text { IF EDAS } \\
\text { GRD }\end{array}$ & IF TOPSIS & \multirow{2}{*}{ IF VIKOR } & $\begin{array}{c}\text { IF VRD } \\
\text { IF EDAS }\end{array}$ & GRD \\
\hline
\end{tabular}




\begin{tabular}{|c|c|c|c|c|c|c|c|c|c|c|c|c|c|c|c|}
\hline Alt & $R$ & Rank & $Q$ & Rank & Rank & $R$ & Rank & $Q$ & Rank & Rank & $R$ & Rank & $Q$ & Rank & Rank \\
\hline $\mathrm{A} 1$ & 0.547 & 1 & 0.312 & 1 & 1 & 0.546 & 2 & 0.334 & 2 & 1 & 0.561 & 1 & 0.323 & 2 & 1 \\
\hline $\mathrm{A} 2$ & 0.527 & 3 & 0.437 & 3 & 3 & 0.335 & 8 & 0.723 & 7 & 8 & 0.410 & 8 & 0.658 & 7 & 8 \\
\hline $\mathrm{A} 3$ & 0.445 & 7 & 0.593 & 6 & 7 & 0.657 & 1 & 0.289 & 1 & 2 & 0.468 & 6 & 0.524 & 5 & 5 \\
\hline A4 & 0.522 & 4 & 0.563 & 4 & 4 & 0.546 & 3 & 0.498 & 3 & 3 & 0.487 & 5 & 0.619 & 6 & 6 \\
\hline A5 & 0.508 & 5 & 0.588 & 5 & 5 & 0.472 & 4 & 0.507 & 4 & 4 & 0.622 & 2 & 0.308 & 1 & 2 \\
\hline A6 & 0.536 & 2 & 0.326 & 2 & 2 & 0.412 & 6 & 0.754 & 8 & 7 & 0.547 & 3 & 0.444 & 3 & 3 \\
\hline A7 & 0.367 & 8 & 0.718 & 8 & 6 & 0.417 & 5 & 0.662 & 5 & 5 & 0.492 & 4 & 0.472 & 4 & 4 \\
\hline A8 & 0.487 & 6 & 0.684 & 7 & 8 & 0.388 & 7 & 0.673 & 6 & 6 & 0.337 & 9 & 0.753 & 9 & 9 \\
\hline A9 & 0.362 & 9 & 0.732 & 9 & 9 & 0.267 & 9 & 0.788 & 9 & 9 & 0.437 & 7 & 0.697 & 8 & 7 \\
\hline
\end{tabular}

Furthermore, the comparison with other MCDM methodologies is given below. In Table 9, the proposed methodology is compared with related studies, where authors observed a fuzzy type, MCDM method, integrated method, groups /individual decision making, and obtained final common ranking of all groups or decision makers. All mentioned features of studies were important to define novelty of the proposed study and to indicate its greater efficiency in comparison with other studies. As can be seen from Table 9, most of the studies used intuitionist fuzzy theory to process uncertain and imprecise information. All studies used EDAS, GRA methods or other as one to obtain alternatives rankings, but only Zhang, Jin and Lin (2013), Mi and Liao (2019) and Karatop et al. (2021) integrated those methods with other MCDM methods. Only Dey, Pramanik and Giri (2015) and Li, Wang and Wang (2018) used group decision making, and to obtain final common ranking of all groups they calculated intuitionistic fuzzy weighted average operator and linguistic neutrosophic power aggregation operator, respectively. But these operators are used as an aggregation of groups' alternatives assessments to form final ranking without knowing previously ranking of each group. Thus, none of the presented related studies made a detail picture of alternatives ranking. Group decision making with various decision makers with different background might seem more time consuming, but this way a better insight into the alternatives assessment by defined criteria can be provided, especially when combining it with intuitionistic fuzzy theory to overcome vagueness and duality. Integration of two or more MCDM methods has proven to be more efficient with more realistic outcome. That is one of the advantages of the proposed methodology regarding related ones. Also, in the proposed research a ranking of each group is obtained, this way an insightful representation of alternatives rankings is provided. Furthermore, approach of integer linear programming and ant colony optimisation is used to obtain final ranking of all groups, taking into account all necessary constrains that decision makers found useful to provide more precise reconstruction ranking that will not only satisfy features of bridges such is safety, stability and functionality, but also financial, spatial and temporal characteristics of the projects' demands.

The criteria weights in the proposed study are calculated using IFPR matrix obtained by fractional programming, consequently, consistency measure is needed to be defined which was not a case in related studies. Hereby, an approach for consistency is defined with its properties and proves, and the threshold was determined to be greater than 0.90. Also, integration of IF likelihood and intuitionistic fuzzy property is used to define the approach for alternatives assessments aggregation. The proposed methodology, as it was mentioned before, used both ideal solutions and average solution in regard to related studies that only used ideal solutions or average one. Finally, to summarize all mentioned, the proposed intuitionistic DS model base on the EDAS and grey relational degree with integration of ILP-ACO has proven to be novel and better in comparisons with the related studies.

Table 9

Comparison with other related MCDM studies.

\begin{tabular}{|c|c|c|c|c|c|}
\hline Related MCDM studies & Fuzzy Type & MCDM method & $\begin{array}{c}\text { Integrated } \\
\text { method }\end{array}$ & GDM & $\begin{array}{l}\text { Final common } \\
\text { ranking }\end{array}$ \\
\hline Wei et al. (2011) & Intuitionistic & GRA & - & No & - \\
\hline Zhang, Jin and Lin (2013) & Intuitionistic & GRA & Entropy & No & - \\
\hline Zhang et al. (2014) & $\begin{array}{l}\text { Interval-valued } \\
\text { intuitionistic }\end{array}$ & GRA & - & No & - \\
\hline $\begin{array}{l}\text { Dey, Pramanik and Giri } \\
(2015)\end{array}$ & Intuitionistic & GRA & - & Yes & ITFWAA \\
\hline $\begin{array}{l}\text { Keshavarz Ghorabaee et al. } \\
(2016)\end{array}$ & Fuzzy & EDAS & - & No & - \\
\hline Kahraman et al. (2017) & $\begin{array}{c}\text { Interval-valued } \\
\text { intuitionistic }\end{array}$ & EDAS & - & No & - \\
\hline Peng, Dai and Yuan (2017) & Interval-valued & $\begin{array}{l}\text { MABAC } \\
\text { EDAS }\end{array}$ & - & No & - \\
\hline $\begin{array}{l}\text { Keshavarz Ghorabaee et al. } \\
\text { (2017) }\end{array}$ & Interval type-2 & EDAS & - & No & - \\
\hline $\begin{array}{l}\text { Ilieva, Yankova and } \\
\text { Klisareva-Belcheva (2018) }\end{array}$ & Fuzzy & EDAS & - & No & - \\
\hline
\end{tabular}




\begin{tabular}{|c|c|c|c|c|c|}
\hline Li, Wang and Wang (2018) & Neutrosophic & EDAS & . & Yes & LNPWA \\
\hline Mia and Liao (2019) & Hesitant & BW & EDAS & No & - \\
\hline Ju et al. (2020) & - & EDAS & - & No & - \\
\hline Karatop et al. (2021) & Fuzzy & $\begin{array}{c}\text { AHP } \\
\text { FMEA }\end{array}$ & EDAS & No & - \\
\hline Ye, Zhan and Xu (2021) & Intuitionistic & $\begin{array}{l}\text { PROMETHEE II } \\
\text { EDAS } \\
\end{array}$ & - & No & - \\
\hline Proposed DS model & Intuitionistic & EDAS & $\begin{array}{c}\text { GRA (Grey } \\
\text { relational } \\
\text { degree) }\end{array}$ & Yes & ILP-ACO \\
\hline
\end{tabular}

\subsection{Advantages and disadvantages}

The proposed model is unique, it improves a group decision making-process, and it gives free expression of an DM's attitude that moves the boundaries of the previous decision-making by civil engineers, architects, conservatives, project managers, users etc., on this issue. The advantages of the proposed intuitionistic fuzzy DS model:

(i) It can be applied to any type of decision making with high level of problem complexity. The model has all components needed for the qualitative expert's judgements and final decisions. For this case study, where historic pedestrian bridges are analysed, eight criteria are determined to evaluate and rank bridges, these criteria are specific because they can be applied to other bridges and objects, and their number can be upgraded, if needed.

(ii) It integrates and hybridizes the strengths of two known and practical methods, EDAS and GRD, using ideal solutions and average solution as references.

(iii) It uses fractional programming to gain criteria weights, and further calculates consistency by new developed model for consistency determination.

(iv) It proposes not only an integration of EDAS and GRD method for the group decision-making problems under intuitionistic fuzzy environment, but also a systematic and sustain methodology with technological and managerial advances. It integrates various constrains defined by DMs using linear programing to achieve the main goal in planned financial cycle and uses optimization technique enabling DMs to achieve their goals in time and money limiting situations.

(v) The approach is straightforward, it successfully reflects real life problematics with inherent uncertainties and dualities by using IFS theory, and can be applied on various different, more complex, problems with greater amount of criteria, alternatives, DMs and DGs with different attitudes and strategies. It can effectively produce final decision when there are many groups which rankings need to be united.

(vi) The proposed methodology is well structured and logical, and can be easily implemented in a software. Although, methodology has many advantages, there are some disadvantages. It seems too long and it might be too complicated for some beginners. It demands involvement of too many decision makers, thus, too many interviews and discussions. Also the process of alternatives evaluation is too long. For this reason, in future research directions the focus needs to be put on developing an intelligent expert system that includes all the information about object and can gain relevant outcomes by decreasing the number of conversations with experts. Furthermore, model that will shorten the assessment of alternatives but still give substantial results, will be proposed.

\section{Conclusion}

A new hybrid DS model is created to improve reconstruction planning of historic pedestrian bridges, using group decision making with multicriteria analysis under the intuitionistic fuzzy environment. It is a delicate and complex problem, especially for the civil engineers, architects, and conservative experts as managers of these bridges. To define reconstruction priority ranking of historic pedestrian bridges, many factors such as safety, stability, functionality, environment impact, cultural preservation, etc., needed to be include in decision-making process. In the proposed model, three DGs are formed according to their area of expertise and relevant knowledge. Members of each DG are asked to create a list of relevant criteria according to which safety and stability, complexity of reconstruction, load, cost, functionality, environmental impact, reconstruction duration and preservation of cultural heritage will be used to evaluate bridges for the reconstruction priority. Criteria weights are determined by judgment IF matrices, then priority vector is calculated using IFPR matrix. For each IF matrix, the consistency is determined using newly defined model for consistency determination. Historic bridges are evaluated using defined LVs and IFNs. Aggregated decision matrix is calculated for each DG by IF likelihood function. The EDAS method is fused with GRD, making a new multicriteria approach for the systems with limited, uncertain, and incomplete information, under intuitionistic fuzzy environment. The combination of GRD and EDAS has proved that it can assist in solving sensitive problems and to make adequate decisions that in real-life problems often require an expert support. Values of GRD were calculated for each DG. These values determined the position of each bridge 
in the ranking of each DG. Finally, to obtain a final common ranking, model of ILP-ACO is used. Sensitivity analysis is conducted to gain intervals of weights of criteria within which the same rankings are still obtain. Proposed DS model is compared with other MCDM methods such are IF TOPSIS and IF VIKOR where according to Spearman's rank correlation coefficient, the correlation is higher than 0.9 for both methods.

According to the abovementioned, the newly developed model has proven to be suitable for the considered motive, and because of its flexible character, it could be the starting input for future research on the reconstruction planning of the historic objects. The study contains a quite amount of relevant and qualitative data and information, and although there is no study that deals with the herein described problematic, and uses the proposed methodology, the study gives extensive literature review on the used methods. The utilized MCDM methods are robust, giving distinct results valuable for the group decision-making. Finally, this research offers guidelines for experts, managers and policy makers, and supplies decision makers with valuable support for making reliable and straightforward decisions.

Acknowledgments: This research is partially supported through project KK.01.1.1.02.0027, a project co-financed by the Croatian Government and the European Union through the European Regional Development Fund - the Competitiveness and Cohesion Operational Programme.

Ethical approval: This article does not contain any studies on humans or animals performed by any of the authors.

Funding details: The study received no external funding.

Conflict of interest: The authors declare no conflict of interest.

Informed consent: Informed consent was obtained from all participants included in the study.

Author contributions: All authors contributed to the study conception and design. Material preparation and data collection were performed by KR and JKP. The analysis and algorithm were done by KR. The first draft of the manuscript was written by KR and JKP, then polished by JA and EKZ. All authors read and approved the final manuscript.

\section{References}

1. Adak, S., Jana, S. Dynamical behavior of an epidemic model with fuzzy transmission and fuzzy treatment control. J. Appl. Math. Comput. (2021).

2. Abd, K., Abhary, K. and Marian, R. (2016). Multi-objective optimisation of dynamic scheduling in robotic flexible assembly cells via fuzzy-based Taguchi approach. Computers \& Industrial Engineering, 99, 250-259.

3. Atanassov, K. T. (2017). Type-1 Fuzzy Sets and Intuitionistic Fuzzy Sets. Algorithms, 10(3), 106.

4. Atanassov, K. T. (1986). Intuitionistic fuzzy sets. Fuzzy Sets and Systems, 20(1), 87-96.

5. Atanassov, K. T. and Gargov, G. (1989). Interval valued intuitionistic fuzzy sets. Fuzzy Sets and Systems, 31, 343-349.

6. Atanassov, K.T., Mavrov, D. and Atanassova, V. (2014). Intercriteria Decision Making: A New Approach for Multicriteria Decision Making Based on Index Matrices and Intuitionistic Fuzzy Sets. Issues in IFSs and GNs,11, 1-8.

7. Balasubramaniam, P. and Ananthi, V.P. (2011). Image fusion using intuitionistic fuzzy sets. Information Fusion, 20(2014), 21-30.

8. Boran, F. E. and Akay, D. (2014). A biparametric similarity measure on intuitionistic fuzzy sets with applications to pattern recognition. Information Sciences, 255, 45-57.

9. Boran, F. E., Genc, S., Kurt, M. and Akay, D. (2009). A multi-criteria intuitionistic fuzzy group decision making for supplier selection with TOPSIS method. Expert Systems with Applications. 36,11363-11368.

10. Büyüközkan, G. and Güleryüz, S. (2016). A new integrated intuitionistic fuzzy group decision making approach for product development partner selection. Computers \& Industrial Engineering, 102, 383-395.

11. Cao, Q., Wu, J.C. and Liang, C. (2015). An intuitionistic fuzzy judgement matrix and TOPSIS integrated multi-criteria decision making method for green supplier selection. Journal of Intelligent \& Fuzzy Systems. 28(1),117-126.

12. Cheng, S. M. and Chang, C.H. (2015). A novel similarity measure between Atanassov's intuitionistic fuzzy sets based on transformation techniques with applications to pattern recognition. Information Sciences, 291, 96-114.

13. Chen, S. M., Cheng, S. H. and Chio, C. H. (2016). Fuzzy multiattribute group decision making based on intuitionistic fuzzy sets and evidential reasoning methodology. Information Fusion, 27, 215-227.

14. Chiang, B. C., Tsai, S.L. and Wang, C.C. (2002). Machine Vision-Based Gray Relational Theory Applied to IC marking Inspection. IEEE Transactions on Semiconductor Manufacturing, 15(4), 531-539.

15. Dabous, S. A. (2008). A decision support methodology for rehabilitation management of concrete bridges. Doctoral dissertation, University of Concordia, Montreal, Quebec, Canada.

16. Deng, J. (1982). Control problems of grey systems. Systems and Control Letters, 1(5), 288-94.

17. Dey, P. P., Pramanik, S. and Giri, B.C. (2015). Multi-criteria group decision making in intuitionistic fuzzy environment on grey relational analysis for weaver selection in Khadi institution. Journal of Applied Quantitative Methods, 10(4), 114 . 
18. Dyckhoff, H. and Pedrycz, W. (1984). Generalized means as model of compensative connectives. Fuzzy Sets and Systems. $14(2), 143-154$.

19. Fazlollahtabar, H. and Gholizadeh, H. (2019). Fuzzy Possibility Regression Integrated with Fuzzy Adaptive Neural Network for Predicting and Optimizing Electrical Discharge Machining Parameters. Computers \& Industrial Engineering,140, 106225.

20. Gumus, S., Kucukvar, M. and Tatari, O. (2016). Intuitionistic fuzzy multi-criteria decision making framework based on life cycle environmental, economic and social impacts: The case of U.S. wind energy. Sustainable Production and Consumption, 8, $78-92$

21. Hou, J. (2010). Grey Relational Analysis Method for Multiple Attribute Decision Making in Intuitionistic Fuzzy Setting. Journal of Convergence Information Technology, 5,194-199.

22. Huang, J. and Süer, G. A. (2015). A dispatching rule-based genetic algorithm for multi-objective job shop scheduling using fuzzy satisfaction levels. Computers \& Industrial Engineering, 86, 29-42.

23. Ilieva, G., Yankova, T. and Klisareva-Belcheva, S. (2018). Decision analysis with classic and fuzzy EDAS modifications. Computational and Applied Mathematics, 37(5), 5650-5680.

24. Ju, Y., Lianda, Y., Luis, M., Santibanez Gonzalez, Ernesto D.R., Giannakis, M., Donga, P. and Wange, A. (2020). A new framework for health-care waste disposal alternative selection under multi-granular linguistic distribution assessment environment. Computers \& Industrial Engineering, 145, 106489.

25. Kahraman, C., Keshavaraz Ghorabaee, M., Zavadskas, K., Cevik Onar, S., Yazdani, M. and Outaysi, B. (2017). Intuitionistic fuzzy method: an application to solid waste disposal site selection. Journal of environmental engineering and landscape management, 25(1), 1-12.

26. Karatop, B., Taşkan, B., Adar, E. and Kubat, C. (2021). Decision analysis related to the renewable energy investments in Turkey based on a Fuzzy AHP-EDAS-Fuzzy FMEA approach. Computers \& Industrial Engineering, 151, 106958.

27. Keshavarz Ghorabaee, M., Zavadskas, E.K., Amiri, M. and Turskis, Z. (2016). Extended EDAS method for fuzzy multicriteria decision-making: an application to supplier selection. International Journal of Computers Communications \& Control,11(3), 358-371.

28. Keshavarz Ghorabaee, M., Zavadskas, E.K., Olfat, L. and Turskis, Z. (2015). Multi-criteria inventory classification using a new method of Evaluation Based on Distance from Average Solution (EDAS). Informatica, 26(3), 435-451.

29. Keshavarz Ghorabaee, M., Amiri, M., Zavadskas, E.K., Turskis, Z. and Antucheviciene, J. (2017). A new multi-criteria model based on interval type-2 fuzzy sets and EDAS method for supplier evaluation and order allocation with environmental considerations, Computers \& Industrial Engineering, 112, 156-174.

30. Li, D. F., Wang, Y.C., Liu, S and Shan, F. (2009). Fractional programming methodology for multi-attribute group decision making using IFS. Applied Soft Computing, 9(1), 219-225.

31. Liu, D. and Wang, L. (2019). Multi-attribute decision making with hesitant fuzzy information based on least common multiple principle and reference ideal method. Computers \& Industrial Engineering, 137, 106021.

32. Li, Y. Y., Wang, J.Q. and Wang, T.L. (2018). A linguistic neutrosophic multi-criteria group decision making approach with EDAS method. Arabian Journal for Science and Engineering, 44(3), 2737-2749.

33. Liao, H. and Xu, Z. (2014). Priorities of Intuitionistic Fuzzy Preference Relation Based on Multiplicative Consistency. IEEE Transactions on Fuzzy Systems. 22(6), 1669-1681.

34. Lin, L., Yuan, X.H. and Xia, Z.Q. (2007). Multicriteria fuzzy decision-making methods based on intuitionistic fuzzy sets. Journal of Computer and System Sciences, 73, 84-88.

35. Lin, L., Yuan, X.H. and Xia, Z.Q. (2006). Multicriteria fuzzy decision-making methods based on intuitionistic fuzzy sets. Journal of Computer and System Sciences, 73, 84-88.

36. Lin, S. J., Lu, I.J. and Lewis, L. (2007). Grey Relation Performance Correlations Among Economics, energy use and carbon dioxide emission in Taiwan. Energy Policy, 35, 1948-1955.

37. Liu, P. D. and Yu, X. C. (2014). 2-dimension uncertain linguistic power generalized weighted aggregation operator and its application for multiple attribute group decision making. Knowledge-Based Systems, 57(1), 69-80.

38. Liu, P. D., Zhang, X. and Jin, F. (2012). A multi-attribute group decision-making method based on interval-valued trapezoidal fuzzy numbers hybrid harmonic averaging operators. Journal of Intelligent \& Fuzzy Systems, 23(5), 159-168.

39. Ma, Y. D. and Hu, M.D. (1997). Improved analysis of hierarchy process and its application to multi- objective decision. Syst Eng Theory Pract. 6, 40-44.

40. Mareschal, B. (1988). Weight stability intervals in multicriteria decision aid. European Journal of Operational Research 33 (1), 54-64.

41. Meng, XY., Wu, YQ. Dynamical analysis of a fuzzy phytoplankton-zooplankton model with refuge, fishery protection and harvesting. J. Appl. Math. Comput. 63, 361-389 (2020).

42. Memari, A., Dargi, A., Akbari Jokar, M.R., Ahmad R. and Abdul Rahim A.R., (2019). Sustainable supplier selection: A multicriteria intuitionistic fuzzy TOPSIS method. Journal of Manufacturing Systems, 50, 9-24.

43. Mi, X. and Liao, H. (2019). An integrated approach to multiple criteria decision making based on the average solution and normalized weights of criteria deduced by the hesitant fuzzy best worst method. Computers \& Industrial Engineering, 133, 83-94.

44. Mohammadi, S., Darestani, S. A., Vahdani Modelling, B. and Alinezhad, A. (2020). A Robust Neutrosophic Fuzzy-based Approach to Integrate Reliable Facility Location and Routing Decisions for Disaster Relief under Fairness and Aftershocks Concerns. Computers \& Industrial Engineering, 148, 106734.

45. Nawaz, H.S., Akram, M. Oligopolistic competition among the wireless internet service providers of Malaysia using fuzzy soft graphs. J. Appl. Math. Comput. 67, 855-890 (2021).

46. Peng, X., Dai, J. and Yuan, H. (2017). Interval-valued fuzzy soft decision making methods based on MABAC, similarity measure and EDAS. Fundamenta Informaticae, 152, 373-396. 
47. Poulik, S., Das, S. \& Ghorai, G. Randic index of bipolar fuzzy graphs and its application in network systems. J. Appl. Math. Comput. (2021).

48. Radziszewska-Zielina, E. and Sladowski, G. (2017). Supporting the selection of a variant of the adaptation of a historical building with the use of fuzzy modeling and structural analysis, Journal of Cultural Heritage, 26, 53-63.

49. Rashidi, M., Lemass, B. and Gibson, P. (2010). A Decision Support System for Concrete Bridge Maintenance. $2^{\text {nd }}$ International Symposium on Computational Mechanics and the $12^{\text {th }}$ International Conference on the Enhancement and Promotion of Computational Methods in Engineering and Science, Hong Kong- Macau (Kina) American Institute of Physics (AIP).

50. Rogulj, K., Racetin, I., Kilić Pamuković, J. and Županović, Lj. (2019). Establishment of the inventory of the historic bridges analyzing the maps of Europe in the XIX. Century, in the area of Split-Dalmatia County, Croatia // Proceedings of the International Cartographic Association, 2, 2019/ Fujita, Hamida (edit.).Tokyo: International Cartographic Association,1-5 doi:10.5194/ica-proc-2-108-2019.

51. Stanjukić, D., Zavadskas, E.K., Keshavarz Ghorabaee, M. and Turskis, Z. (2017). An Extension of the EDAS Method Based on the Use of Interval Grey Numbers. Studies in Informatics and Control, 26(1), 5-12.

52. Szmidt, E. and Kacprzyk, J. (2004). A concept of similarity for intuitionistic fuzzy sets and its application in group decision making. in: Proceeding of International Joint Conference on Neural Network \& IEEE International Conference on Fuzzy Systems, Budapest, Hungary, 25-29.

53. Szmidt, E. and Kacprzyk, J. (2000). Distances between intuitionistic fuzzy sets. Fuzzy Sets and Systems. 114 (3), 505518.

54. Szmidt, E., Kacprzyk, J. and Bujnowski, P. (2014). How to measure the amount of knowledge conveyed by Atanassov's intuitionistic fuzzy sets? Information Sciences, 257, 276-285.

55. Vlachos, I. K. and Sergiagis, G.D. (2007). Intuitionistic fuzzy information—application to pattern recognition. Pattern Recognition Letters, 28, 197-206.

56. Wang, Z. J. (2013). Derivation of intuitionistic fuzzy weights based on intuitionistic fuzzy preference relations. Applied Mathematical Modelling. 37, 6377-6388.

57. Wang, Z., Rodríguez, R. M., Wang, Y. and Martínez, L. (2020). A two-stage minimum adjustment consensus model for large scale decision making based on reliability modelled by two-dimension 2-tuple linguistic information. Computers \& Industrial Engineering, 106973.

58. Wei, G. W. (2010). GRA method for multiple attribute decision making with incomplete weight information in intuitionistic fuzzy setting. Knowledge-Based Systems, 23(3), 243-247.

59. Wei, G., Wang, H. J., Lin, R. and Zhao, X. (2011). Grey Relational Analysis Method for Intuitionistic Fuzzy Multiple Attribute Decision Making with Preference Information on Alternatives. International Journal of Computational Intelligence Systems, 4(2), 164-173.

60. Xia, M. and Xu, Z. (2012). Entropy/cross entropy-based group decision making under intuitionistic fuzzy environment, Information Fusion, 13 (1), 31-47.

61. Xu, Z. S. (2008). Dynamic intuitionistic fuzzy multi-attribute decision making. International Journal of Approximate Reasoning, 48(1), 246-262.

62. Xu, Z. S. (2007a). Intuitionistic fuzzy aggregation operators. IEEE Trans. Fuzzy Syst, 15(6),1179-1187.

63. Yang, M.-F. and Lin, Y. (2013). Applying fuzzy multi-objective linear programming to project management decisions with the interactive two-phase method. Computers \& Industrial Engineering, 66(4), 1061-1069.

64. Ye, J., Zhan, J. and Xu, Z. (2021). A novel multi-attribute decision-making method based on fuzzy rough sets. Computers \& Industrial Engineering, 155, 107136.

65. Zadeh, L.A. (1965). Fuzzy sets, Information and Control, 8(3), 338-353.

66. Zhang, X., Jin, F. and Lin, P. (2013). A grey relational projection method for multi-attribute decision making based on intuitionistic trapezoidal fuzzy number. Applied Mathematical Modelling, 37(5), 3467-3477.

67. Zeng, S, Chen, S.M. and Kuo L.W. (2019). Multiattribute decision making based on novel score function of intuitionistic fuzzy values and modified VIKOR method. Information Science, 488, 76-92.

68. Zhang, S. F. and Liu, S.Y. (2019). A GRA-based intuitionistic fuzzy multi-criteria group decision making method for personnel selection. Expert Systems with Applications 38, 11401-11405.

69. Zhang, Q., Xing, H., Liu, F. and Huang, Y. (2014). An enhanced grey relational analysis method for interval-valued intuitionistic fuzzy multiattribute decision making. Journal of Intelligent \& Fuzzy Systems, 26(1), 317-326.

70. Zhang, X. M. and Xu, Z.S. (2012). A new method for ranking intuitionistic fuzzy values and its application in multiattribute decision making. Fuzzy Optimization and Decision Making. 12, 135-146. 